Brandes, C. M., Kushner, S. C., Herzhoff, K., \& Tackett, J. L. (in press). Facet-level personality development in the transition to adolescence: Maturity, disruption, and gender differences. Journal of Personality and Social Psychology.

\title{
Facet-Level Personality Development in the Transition to Adolescence: Maturity, Disruption, and Gender Differences
}

\author{
Cassandra M. Brandes ${ }^{1}$ \\ Shauna C. Kushner ${ }^{2}$ \\ Kathrin Herzhoff ${ }^{3}$ \\ Jennifer L. Tackett ${ }^{1}$ \\ ${ }^{1}$ Northwestern University, USA \\ ${ }^{2}$ Toronto, ON, Canada \\ ${ }^{3}$ McLean Hospital, Harvard Medical School
}

\begin{abstract}
Author Note
Correspondence regarding this article should be addressed to Cassandra Brandes, Department of Psychology, Northwestern University, Evanston, IL 60208.

Email: cbrandes@u.northwestern.edu

The authors have no conflicts of interest to disclose.
\end{abstract}

This is a pre-print of a manuscript in press and not the official copy of record. 


\begin{abstract}
The transition to adolescence is marked by enormous change in social, biological, and personality development. Although accumulating evidence has offered insight into the nature of higher-order personality trait development during this period, much less is known about the development of lower-order personality traits, or "facets". The current study employed a cohortsequential longitudinal design to examine domain- and facet-level trajectories for motherreported personality traits during the early adolescent transition. Personality trait domains and facets were assessed with the Inventory of Child Individual Differences - Short Form (Deal et al., 2007). Participants were 440 children followed at four annual timepoints from middle childhood $\left(M_{\text {Age }}=9.97, S D=0.81\right)$ to early adolescence $\left(M_{\text {Age }}=13.11, S D=0.84\right)$. Results of latent growth curve models showed substantial facet-level personality stability in this period, as well as small to moderate linear change in 13 of 15 facets. Gender differences in change were evident for 9 facets. Overall patterns suggested consistent increases in agreeableness facets with null to small gender differences. Neuroticism and openness to experience facet change was heterogeneous within each domain, but patterns were similar for boys and girls. Extraversion primarily decreased, though the magnitude and direction of change differed between facets and genders. Conscientiousness increased across all facets, but only among girls. These findings overall demonstrate a high degree of developmental consistency in facets within each domain as well as some notable differences. Further, this study contributes to a small and somewhat mixed evidence base for current theories of adolescent personality development.
\end{abstract}

Keywords: Personality development, stability, change, facets, adolescence 
Facet-level personality development in the transition to adolescence:

Maturity, disruption, and gender differences

As individuals grow from children into adults, they tend to become ever more selfregulated and prosocial - a phenomenon known as the maturity principle (Bleidorn et al., 2013; Roberts et al., 2005). However, the road from childhood to adulthood is neither a short nor a smooth one; in fact, the transition from childhood to adolescence is a time of dramatic physical, social, and psychological change (Steinberg \& Sheffield Morris, 2001). During this period, some researchers have observed that teens tend to temporarily become more dysregulated and antisocial, a phenomenon known as the disruption hypothesis (Soto et al., 2011; Soto \& Tackett, 2015). The exact nature and timing of maturity and disruption processes remains ambiguous, however. Developmental studies of early personality are sparse, particularly relative to such work in adult populations, and their synthesis is clouded by inconsistent measurement approaches.

The majority of studies on child personality development have examined higher-order, domain-level traits within the Five Factor Model of personality (Soto \& Tackett, 2015). These studies have also primarily covered large swaths of development (e.g., 10-20 years) or largerscale developmental changes in the transition from childhood to adulthood. However, focusing on domain-level traits and on long time periods results in a lack of specificity about precisely what personality content is changing, and when. In the present study, we investigated personality rank-order stability and mean-level change from middle childhood to adolescence within narrowband personality facets using parent reports. This study can be contextualized within several personality developmental theories, a literature to which we now turn.

\section{Personality Theories of Stability \& Change}


Rank-order stability (or consistency) refers to the extent to which individuals remain the same relative to one another in their ranking on personality traits across time (Caspi et al., 2005). Multiple meta-analyses have indicated that the average rank-order stability of personality traits is moderate (e.g., $r \sim .50-.70$ ), and increases across the life span from childhood into middle age (approximately 50-60 years) before declining slightly into old age (Ferguson, 2010; Roberts \& DelVecchio, 2000; Roberts \& Nickel, 2017). This phenomenon is known as the cumulative continuity principle. In childhood, stability coefficients - generally estimated via Pearson correlations - across all traits in the Five Factor Model range from approximately . 30 at age 3 to .60 or higher in adolescence (Ferguson, 2010; Roberts \& DelVecchio, 2000; Soto \& Tackett, 2015). The consistency of temperament — a construct highly overlapping with personality (De Pauw, 2017; Tackett et al., 2013)—-likewise ranges from approximately .30 (Kopala-Sibley et al., 2018) to approximately .50 (Durbin et al., 2007) in studies of children as young as 3 years. Meanwhile, stability estimates may reach up to .80 or more in middle adulthood (Roberts \& DelVecchio, 2000; Soto \& Tackett, 2015). While more short-term measurement occasions (e.g., 5-year intervals) evidence higher stability coefficients than long-term ones (e.g., 20-year intervals), stability estimates do not approximate zero even across long periods (Fraley \& Roberts, 2005; Hampson \& Goldberg, 2006).

Mean-level changes refer to differences in average (mean) levels of traits between age groups (Roberts et al., 2006). Research typically indicates that the magnitude of mean-level changes in personality is small (e.g., $d \sim .10$ to .20 ), though the direction of these changes varies by trait and by developmental epoch (Caspi et al., 2005; Soto \& Tackett, 2015). Robust patterns of mean-level change in child and adolescent personality are often discussed in the context of two primary perspectives: the maturity principle and the disruption hypothesis. 
The maturity principle describes the tendency for individuals to continuously decrease in neuroticism and increase in agreeableness and conscientiousness from childhood to adulthood (Bleidorn et al., 2009, 2013; Caspi et al., 2005; Roberts et al., 2006; Soto et al., 2011). This uptick in socially desirable traits may reflect an overall developmental process of increasing responsibility and social skill (i.e., maturity) that aligns with societal expectations for adult, relative to child, behavior. This pattern of mean-level changes has been observed over longitudinal studies of more than 40 years of time, across genders, and in a variety of cultural contexts (Bleidorn et al., 2013), and it is assumed to be a "generally linear" (Roberts, 2018) trend. Decreases in extraversion have also been observed from childhood to adulthood, though findings in this realm are less consistent. Some evidence suggests that extraversion shows facetspecific and quadratic change over this time, rather than homogenous, linear changes across all facets in this domain (McCrae et al., 2002; Roberts et al., 2006; Soto et al., 2011).

Hypotheses regarding the mechanisms of maturity largely attribute desirable changes to normative biological, cognitive, and social maturation (Roberts, 2018; Roberts \& Nickel, 2017). Social maturation specifically assumes that changes come from compensatory responses to the familial, romantic, and occupational demands placed on individuals as they move into adult roles, also known as social investment theory (Lodi-Smith \& Roberts, 2007; Roberts, 2018; Roberts \& Jackson, 2008). Social investment theory has been consistently supported, with higher engagement in work and romantic relationships predicting personality maturity (Hudson et al., 2012; Hudson \& Roberts, 2016). However, this process may not hold for all life transitions (namely, the transition to parenthood; van Scheppingen et al., 2016), and the maturity principle may not be as continuous a developmental trend as it is often assumed to be. 
The disruption hypothesis describes the case of short-term recession in socially desirable personality traits during adolescence. Several studies have found that teenagers may temporarily decrease in levels of agreeableness, conscientiousness, and openness to experience; this downward trend then tends to reverse between late adolescence and early adulthood (De Fruyt et al., 2006; Denissen et al., 2013; Luan et al., 2017; Ong et al., 2018; Soto et al., 2011; Soto \& Tackett, 2015; Tackman et al., 2017; van den Akker et al., 2010). This disruption pattern is taken to reflect a transitory shift toward harshness and irresponsibility corresponding with the stress and changes accompanying puberty and adolescent social dynamics (Soto \& Tackett, 2015). Though this pattern of mean-level changes has been observed both cross-sectionally and longitudinally, the exact timing of the disruption process between childhood and late adolescence is yet unclear, with some studies suggesting earlier onset (age 9-10; Ong et al., 2018; Soto et al., 2011; Tackman et al., 2017), and others suggesting later (age 12-13; De Fruyt et al., 2006). Further, Slobodskaya and Akhmetova (2010) showed that disruption in agreeableness may occur even later (age 15+), and they failed to find a pattern of disruption in conscientiousness and neuroticism. While the aforementioned studies have included samples from Western Europe, North America, Singapore, and Russia, among other countries, differences in findings are not fully explained by differences in the geographic location or demographics of the samples. While these findings do not negate the existence of a lifespan trend toward personality maturity, they call into question the assumed continuous nature of socially desirable personality change.

Mechanistic explanations for the disruption hypothesis have not been examined nearly as extensively as mechanistic explanations for the maturity principle. However, preliminary hypotheses propose that the rapid psychological, biological, and social changes of adolescence (Soto \& Tackett, 2015; Steinberg \& Sheffield Morris, 2001) may contribute to temporary 
downward trends in socially desirable traits. Five-Factor Model traits reflect heterogeneous patterns of thoughts, feelings, and behaviors. Thus, it is yet unclear whether the disruption process is one of homogenous decreases in self-regulation (for example), or if only some specific behavioral patterns (e.g., increased risk-taking) drive this observation at the higher-order trait level. Further research on the mechanisms of personality disruption require identification of those specific facet-level patterns that may contribute to domain-level disruption.

\section{The Bandwidth-Fidelity Tradeoff: Constructs and Developmental Periods}

In psychometrics, researchers face a dilemma known as the bandwidth-fidelity tradeoff; metaphorically, a "choice between binoculars and a microscope" (Cronbach \& Gleser, 1965; Hogan \& Roberts, 1996). High bandwidth instruments are multidimensional, capturing a variety of loosely correlated psychological features. These measures are often more robust to measurement error and predict a variety of broad, important life outcomes from occupational success to relationship quality and more (e.g., Hogan \& Roberts, 1996; Mroczek \& Spiro, 2007; Poropat, 2014; Tackett et al., 2014). High fidelity instruments, on the other hand, have lower dimensionality, capturing narrower sets of strongly correlated psychological features. These measures are highly internally consistent, often better predict closely related outcomes, and may provide more specific information about what aspects of a psychological construct may be related to the outcome of interest (Mõttus et al., 2019; Paunonen \& Ashton, 2001). Bandwidth (i.e., dimensionality) and fidelity (i.e., internal consistency) are themselves continuous attributes of measurement and inevitably, increasing one decreases the other ${ }^{1}$ (Paunonen et al., 1999).

\footnotetext{
${ }^{1}$ The bandwidth-fidelity tradeoff can be somewhat circumvented where the scientist opts to increase the size of the item pool (Paunonen et al., 1999) or utilize adaptive testing under an item response theory framework (D. J. Weiss, 1982). However, in the average case where test length is a practical concern and classical test theory is used, there is a direct negative relationship between bandwidth and fidelity.
} 
There are a variety of levels of bandwidth/fidelity with which personality traits can be described, with the "Big Five," or Five Factor Model being perhaps the most commonly studied level of analysis (Caspi et al., 2005). However, other levels of analysis may include higher-order factors, facets, or even item-level "nuance” traits (e.g., DeYoung, 2006; Digman, 1997; McCrae, 2015). Each of these levels of analysis has different strengths and weaknesses. The Big Five show strong predictive validity (Soto, 2019). For example, conscientiousness is a well-known predictor of all-cause mortality (e.g., Graham et al., 2017). However, this correlation may imply that everything from achievement-oriented behaviors to conventionality (two facets of conscientiousness) influence the likelihood of dying. In fact, researchers find that this relationship is primarily driven by a self-discipline facet, or more specifically, by health behaviors (e.g., smoking; Turiano et al., 2015; A. Weiss \& Costa, 2005). Examining individual behaviors has its own drawbacks, though—namely, measurement error, retrospective reporting bias, and other informant-specific biases for which domain-level analyses may better control (Schmidt \& Hunter, 1996). Therefore, it is critical to examine multiple levels of the personality hierarchy to understand precisely how individual differences function.

Examining multiple levels of construct specificity is particularly relevant for longitudinal research, as subordinate dimensions of high-bandwidth measures sometimes change in opposite directions over a developmental period (e.g., anxiety and depression are facets of internalizing psychopathology, but have different developmental trajectories; Van Oort et al., 2009). Opposing directions of mean-level changes among facets within a trait domain may have a suppression effect at the domain level (Paunonen et al., 1999). Despite this, substantially less research has investigated children's lower-order traits. Similarly, most longitudinal research in personality development covers high-bandwidth measurement intervals. Administering multiple tests over a 
10-40 year period (e.g., Bleidorn et al., 2009; Hampson \& Goldberg, 2006) will produce a robust measure of long-term change, though identifying exactly when changes occurred will be difficult. Therefore, there is a need for more frequent assessments of personality during critical developmental windows to understand specifically when and how changes occur.

\section{Facet-Level Personality Development}

Most knowledge on mean-level changes in personality facets in childhood comes from studies using just one or two measurement points. Several consistent findings have emerged from these studies: first, activity (a facet of extraversion) shows more dramatic decline across childhood and adolescence than do other facets by both self- and parent-report (De Fruyt et al., 2006; Slobodskaya \& Akhmetova, 2010; Soto et al., 2011). Second, achievement orientation (a facet of conscientiousness) shows greater decline in adolescence than do other facets by teacherand parent-report (De Fruyt et al., 2006; Prinzie \& Deković, 2008). Third, intellect (a facet of openness to experience) frequently diverges from creativity/imagination facets such that it either shows null or smaller declines with age by teacher- and parent-report (while creativity/imagination show greater declines; De Fruyt et al., 2006; Prinzie \& Deković, 2008). Fourth, anxiety, or fearfulness (a facet of neuroticism) is more variable by age and gender, such that both increases and decreases are found, depending on the age group and gender examined. Other facets of neuroticism have less consistent age differences across a variety of raters (De Fruyt et al., 2006; Prinzie \& Deković, 2008; Soto et al., 2011). Facet-level studies of adult personality show some similarities to those of children, including that facets of extraversion and openness show perhaps the most uniqueness in their development over time (Bleidorn et al., 2009; Schwaba et al., 2019; Terracciano et al., 2005) and that neuroticism and agreeableness facets are largely consistent with domain-level changes (e.g., Soto et al., 2011). However, adults 
generally do not show the same differentiation of achievement orientation within conscientiousness (Bleidorn et al., 2009; Jackson et al., 2009; Terracciano et al., 2005). Although other age differences in trait facets have been reported in the child-adolescent period (e.g., temperament facets; Durbin et al., 2007), a lack of agreement on the lower-order structure of child personality measures makes comparison across studies difficult (De Pauw, 2017; Tackett et al., 2013).

While several previous multi-wave longitudinal studies have examined stability and change in adults' lower-order personality traits (e.g., Bleidorn et al., 2009), to our knowledge, only one previous study has assessed facet-level personality change continuously (i.e., across more than two waves) in a pre-adolescent sample (de Haan et al., 2017). In a study by de Haan and colleagues (2017), researchers used a cohort-sequential design to investigate stability and change in mother-reported child personality facets from 2-4.5 years and 6-17 years in two separate Flemish samples. They found that during the 6-17 year period, change within each Five Factor Model trait was not homogenous across facets as measured by the Hierarchical Personality Inventory for Children (HiPIC; Mervielde \& De Fruyt, 1999). Neuroticism (i.e., reversed HiPIC Emotional Stability), extraversion, conscientiousness, agreeableness (i.e., HiPIC Benevolence), and openness to experience (i.e., HiPIC Imagination) showed facet-specific changes from ages 6-17. Further, trajectories of HiPIC facets Anxiety (neuroticism), SelfConfidence (neuroticism), Expressiveness (extraversion), Achievement Striving (conscientiousness), Orderliness (conscientiousness), Perseverance (conscientiousness), Dominance (agreeableness), and Altruism (agreeableness) differed significantly between boys and girls, with girls generally showing trends of greater (or earlier) maturity in facets of conscientiousness and agreeableness and greater (or earlier) disruption in facets of neuroticism. 
These findings also corroborate prior research on gender differences in personality development (Soto et al., 2011). Overall, results suggested that lower-order traits did not conform to general trends of either maturity or disruption during this period. However, given that de Haan and colleagues (2017) and the majority of previous two-wave studies on personality facet change in childhood and early adolescence has used the same assessment (the Hierarchical Personality Inventory for Children), it is unknown to what extent these results generalize beyond a single measure. Although popular measures of child personality are strongly related at the domain level, they differ quite a bit at the facet level (Tackett et al., 2013).

\section{The Present Study}

The present study aims to investigate the stability and change of parent-reported lowerorder personality traits (facets) within each Five Factor Model domain, and the extent to which facet trait development may evidence maturity or disruption in the developmental period from middle childhood to adolescence. To investigate how facet-level personality traits develop over this period, we estimated Pearson correlations and polynomial latent growth curves among a sample of 440 youth. Mother-reported personality was assessed annually over a period of approximately four years using the Inventory of Children's Individual Differences, a Five Factor Model personality measure that was empirically derived and validated for children and adolescents (Deal et al., 2007). We examined stability and change in a cohort-sequential longitudinal design, with age groups from 9-13 years. To examine gender differences in trait development, we also conducted analyses separately for boys and girls. These analyses were registered prospectively, prior to data cleaning. This preregistration can be found on the Open Science Framework (OSF) at https://osf.io/q48kc, and it details the following hypotheses based on prior research in this area (Caspi et al., 2005; De Fruyt et al., 2006; de Haan et al., 2017; 
Prinzie \& Deković, 2008; Slobodskaya \& Akhmetova, 2010; Soto et al., 2011; Soto \& Tackett, 2015):

1. Higher-order domains Agreeableness, Conscientiousness, Extraversion, and Openness will decline mildly over this period, and Neuroticism will increase, but only among girls;

2. Achievement Orientation will decrease to a greater extent than other facets of Conscientiousness, and this change will be more pronounced for males than for females;

3. Activity Level and Positive Emotions will decrease to a greater extent than other facets of Extraversion;

4. Fear will increase over this period, but only among girls;

5. Overall, personality rank-order stability will be moderate over this period (Cohen's d $[.35, .65])$; and

6. Any personality trait change will be small over this period (Cohen's $d[.10, .35]$ ), corresponding to $T$-score changes between approximately 1-4.

\section{Method}

\section{Participants}

Participants were 440 mothers of children (50.2\% girls) from a four-wave longitudinal study of personality development during the transition from middle childhood to early adolescence. Participant demographic characteristics and numbers by collection wave are summarized in Table 1. The sample size was determined prospectively based on the ability to detect typical effects in personality research (e.g., correlations around .20 and above) with $80 \%$ power. During the initial wave of this study, primarily 9 - to 10 -year old youth $(M=9.97, S D=$ 0.81) and their parents were recruited using a community-based participant pool and through flyers posted throughout the community. Approximately one year $\left(\mathrm{M}_{\mathrm{T} 1-\mathrm{T} 2}=1.18, \mathrm{SD}_{\mathrm{T} 1-\mathrm{T} 2}=0.27\right.$; 
$\left.\mathrm{M}_{\mathrm{T} 2-\mathrm{T} 3}=0.94, \mathrm{SD}_{\mathrm{T} 2-\mathrm{T} 3}=0.31 ; \mathrm{M}_{\mathrm{T} 3-\mathrm{T} 4}=0.97, \mathrm{SD}_{\mathrm{T} 3-\mathrm{T} 4}=0.24\right)$ elapsed between the initial and each subsequent wave, with (unsurprising) variability among participants depending on ease of scheduling follow-up assessments. Inclusion criteria were fluency in English in both the caregiver and child, and exclusion criteria were the presence of neurodevelopmental disorders, psychotic disorders, or intellectual disability in the child. Informed consent was obtained from parents, and verbal assent was obtained from child participants. Ethics approval was obtained from the University of Toronto Research Ethics Board (protocol number 19353; "Child Personality and Behavioral Outcomes").

Table 1

Participant Demographic Characteristics

\begin{tabular}{|c|c|c|c|c|}
\hline Characteristic & $\begin{array}{c}\text { Wave } 1 \\
(N=328)\end{array}$ & $\begin{array}{c}\text { Wave } 2 \\
(N=237)\end{array}$ & $\begin{array}{c}\text { Wave } 3 \\
(N=355)\end{array}$ & $\begin{array}{c}\text { Wave } 4 \\
(N=310)\end{array}$ \\
\hline Youth Age Mean (SD) & $9.97(0.81)$ & $11.11(0.89)$ & $12.09(0.81)$ & $13.11(0.84)$ \\
\hline \multicolumn{5}{|l|}{ Youth Gender $(n)$} \\
\hline Male & 161 & 113 & 168 & 152 \\
\hline Female & 167 & 124 & 187 & 158 \\
\hline \multicolumn{5}{|l|}{ Youth Ethnicity (\%) } \\
\hline Caucasian & $70 \%$ & $72 \%$ & $70 \%$ & $70 \%$ \\
\hline Asian-Canadian & $9 \%$ & $9 \%$ & $9 \%$ & $8 \%$ \\
\hline African-Canadian & $3 \%$ & $2 \%$ & $3 \%$ & $2 \%$ \\
\hline Hispanic & $0.3 \%$ & $0.4 \%$ & $0.3 \%$ & $0.3 \%$ \\
\hline Other & $17 \%$ & $17 \%$ & $19 \%$ & $20 \%$ \\
\hline \multicolumn{5}{|l|}{ Parent Marital Status (\%) } \\
\hline Married/living with partner & - & - & - & $88 \%$ \\
\hline Divorced/separated & - & - & - & $8 \%$ \\
\hline Widowed & - & - & - & $2 \%$ \\
\hline Never Married & - & - & - & $2 \%$ \\
\hline \multicolumn{5}{|l|}{ Parent Education (\%) } \\
\hline Postsecondary degree/diploma & - & - & - & $87 \%$ \\
\hline Some postsecondary education & - & - & - & $7 \%$ \\
\hline Completed high school & - & - & - & $5 \%$ \\
\hline Some high school & - & - & - & $0.6 \%$ \\
\hline Parent Employment Status (\%) & & & & \\
\hline
\end{tabular}




\begin{tabular}{|c|c|c|c|c|}
\hline Employed full-time & - & - & - & $58 \%$ \\
\hline Employed part-time & - & - & - & $22 \%$ \\
\hline Stay-at-home caregivers & - & - & - & $14 \%$ \\
\hline Unemployed & - & - & - & $2 \%$ \\
\hline Students & - & - & - & $2 \%$ \\
\hline Retired & - & - & - & $0.6 \%$ \\
\hline Medical or psychiatric disability & - & - & - & $0.6 \%$ \\
\hline \multicolumn{5}{|l|}{ Annual household income (CAD) $(\%)$} \\
\hline Less than $\$ 20,000$ & - & - & - & $10 \%$ \\
\hline Between $\$ 20,000$ and $\$ 40,000$ & - & - & - & $9 \%$ \\
\hline Between $\$ 40,000$ and $\$ 60,000$ & - & - & - & $11 \%$ \\
\hline Between $\$ 60,000$ and $\$ 80,000$ & - & - & - & $14 \%$ \\
\hline Between $\$ 80,000$ and $\$ 100,000$ & - & - & - & $14 \%$ \\
\hline More than $\$ 100,000$ & - & - & - & $35 \%$ \\
\hline
\end{tabular}

Note. Details on marital status, education, employment, and household income were obtained from caregivers during the final wave of the study and therefore reflects this subset of the total sample.

\section{Measures}

Inventory of Children's Individual Differences - Short Form (ICID-S; Deal et al., 2007)

Children's personality traits were assessed using the ICID-S, a 50-item parent-report questionnaire which assesses five higher-order traits (roughly analogous to the Five Factor Model) and 15 lower-order facets (Goldberg, 2001; Tackett, Slobodskaya, et al., 2012). These traits included Neuroticism (facets: Fear, Negative Affect, Shy), Extraversion (facets: Positive Emotions, Sociable, Considerate, Activity Level), Conscientiousness (facets: Organized, Achievement Orientation, Distractible_-reverse-coded), Agreeableness (facets: Antagonism and Strong Willed—-both reverse-coded), and Openness to Experience (facets: Intellect and Openness). We also included the facet Compliant, which has cross-loadings on Conscientiousness and Agreeableness in Deal and colleagues (2007), but does not have a respective higher-order domain in the simple structure scoring preregistered (and used) here. However, Compliant was retained for analysis given the emphasis in this study on facet-level 
specificity, not only domain-level development. Items were rated on a 7-point scale $(1=$ much less than the average youth and $7=$ much more than the average youth). Given that only the short form was used at the fourth assessment wave and all short form items were drawn from the 144-item long form (Halverson et al., 2003), only the 50 ICID-S items were selected from among the ICID long form administered in the first three waves. Across all four waves, internal consistency (coefficient $\alpha$ ) ranged from .84 to .88 for Neuroticism, .89 to .91 for Extraversion, .83 to .86 for Openness, .81 to .84 for Agreeableness, and .89 to .91 for Conscientiousness. Facet-level internal consistencies ranged from .73 (T1 Distractible and T2 Antagonism) to .90 (T4 Considerate). Full descriptives and reliabilities can be found on the OSF page for this project, as can both forms of the ICID measure (https://osf.io/8crwz/).

\section{Procedure}

Data for the present investigation were collected as part of a larger longitudinal study, the Child Personality and Behavioral Outcomes Study-Toronto. ${ }^{2}$ Some portions of the data from this study have been used in prior publications (Brandes et al., 2019; Shields et al., 2019, as well as those listed in the preregistration for this project: https://osf.io/q48kc); however, no prior publications investigated facet-level personality change or used personality data from all four measurement occasions. Questionnaires were completed either in the lab or at the participants' homes and returned to the lab by mail. During the first wave of the study, caregiver-reports were obtained during an in-lab assessment; in the third wave, caregiver-reports were collected in the lab or for a small subset $(n=65)$, by mail; for the second and fourth waves, caregiver-reports were collected via mail. Participant retention varied across waves, ranging from $69.1 \%$ at the second wave, to $79.5 \%$ and $80 \%$ at the third and fourth waves, respectively. An additional 93

\footnotetext{
${ }^{2}$ As participants did not consent to the sharing of individual-level data, these data cannot be made publicly available. However, detailed descriptives and correlation matrices are shared on the OSF page for this project.
} 
families were recruited at the third wave using the same initial recruitment methods to account for attrition. Families received various combinations of monetary compensation and gifts for the children at different waves, depending on the extent of participation at each wave; compensation increased for participation at subsequent waves. For a comprehensive account of all measures and informants collected in this study, please see the OSF page for the Child Personality and Behavioral Outcomes Study_-Toronto (https://osf.io/9ywzm/).

\section{Data Analysis Plan}

Analyses for this project were preregistered on the OSF prior to data cleaning of the full, multi-wave dataset, and any deviations from the preregistration are noted in Deviations from the Preregistration. Analyses were conducted using the psych, lavaan, semTools, and BaylorEdPsych packages in R (Beaujean, 2012; R Core Team, 2017; Rosseel, 2012; semTools Contributors, 2016). As participants were heterogeneous with respect to age at each timepoint of data collection, we binned participant data into five age groups (ages: 9-9.99 years; 10-10.99 years, 11-11.99 years, 12-12.99 years, and 13-13.99 years). All mean-level change and year-to-year stability analyses were conducted with these age groupings as the time variable. Domain-level results were included alongside facet-level results for descriptive comparison.

Little's MCAR test (Little \& Rubin, 2014) was conducted to examine multivariate missingness due to attrition by collection wave, and these tests did not indicate that data were likely missing based on personality facets $\left(\chi^{2}\right.$ range $[19.48,37.26]$, all $p$ 's $\left.>.05\right)$, and thus, an assumption of missing at random was tenable (see Supplemental Table 1 on the OSF page for this project for full missingness results; https://osf.io/8crwz/). Maximum likelihood estimation was used for all structural equation models, and full information maximum likelihood (FIML) was used to account for missing data. Models were compared on the basis of model chi-square, 
comparative fit index (CFI), Tucker-Lewis Index (TLI), root mean square error of approximation (RMSEA), standardized root mean square residual (SRMR), Akaike information criterion (AIC), and Bayesian information criterion (BIC). Using recommendations from Browne \& Cudeck (1992), good fit was considered to include CFI and TLI values less than or equal to 0.95, RMSEA less than or equal to .05, and SRMR values less than or equal to .06. Adequate fit was considered to include CFI and TLI values greater than or equal to .90 and RMSEA less than or equal to .10. Lower values of AIC and BIC indicate better fit. All analytic code is archived on the OSF page for this project.

\section{Measurement Invariance Analyses}

In order for latent growth analyses to be interpretable, measurement invariance must be established to ensure that the selected construct is being measured consistently across different time points (Meredith, 1993). To test for measurement invariance, we used confirmatory factor analysis (CFA) to fit item-level models for each facet as specified in the original scoring, as well as domain-level models with correlated facets (Deal et al., 2007). We first examined whether the fit of the same model for each domain and facet was substantially different between timepoints, as well as between gender within each timepoint. We then iteratively constrained the (1) loadings, (2) intercepts, and (3) residuals to equality across time to test for (1) metric/weak, (2) strong/scalar, and (3) strict/full measurement invariance. Significant decrements in model fit at each level were taken to indicate non-invariance, and the less constrained model was therefore retained. Significance of chi-squared difference tests was pre-registered at the conventional threshold of $\alpha=.05$. As achieving full measurement invariance is atypical with this type of data and given the relative rarity of this quantity and type of developmental data, we preregistered our minimal threshold liberally at configural invariance. However, results of models in which at least 
metric invariance was not achieved are highlighted to facilitate more cautious interpretation (see Results).

\section{Stability Analyses}

We estimated Pearson correlations between adjacent age bins and between the first (T1) and last (T4) time points assessed. The comparison between measurements at 9 and 13 years lacked statistical power $(n=14)$ because very few participants who entered the study at age 9 submitted fourth wave data at age 13, expectedly given the accelerated longitudinal nature of the data. Therefore, we report correlations between traits measured at the first and last timepoints (T1 to T4, $n=223$ ), though participant ages were heterogenous within each collection wave. Average time between $\mathrm{T} 1$ and $\mathrm{T} 4$ measurements was 3.14 years $\left(\mathrm{SD}_{\mathrm{T} 1-\mathrm{T} 4}=0.38\right.$ years $)$. Correlations between traits from ages 9 to 12 years $(n=97)$ can be found on the OSF page for this project (https://osf.io/8crwz/). To determine if facets within each domain showed differential stability across this period (e.g., to compare r's for Sociability from T1 to T4 and Positive Emotions T1 to T4), Steiger tests were conducted for comparisons of dependent correlations (Steiger, 1980). Correlations (i.e., stabilities) of different facets were considered dependent, as they were taken from the same sample, and there was reason to assume that all personality variables would be correlated to some degree. Steiger tests account for the intercorrelations of the variables being tested (e.g., T1 Sociability with T1 Positive Emotions) and convert both stability estimates (correlations) to $z$ values prior to testing these $z$ values for significant differences. To determine if stability coefficients differed for boys and girls, Fisher's $r$-to-z tests of independent correlations were conducted, which likewise transforms stabilities to $z$ values before computing the $z$ statistic of the difference between $z$-transformed stabilities. As boys and 
girls constituted nonoverlapping samples, stabilities were treated as independent correlations.

Each of these $z$ tests were conducted with the same decision criterion of $\alpha=.05$.

\section{Latent Growth Analyses}

We used polynomial latent growth curve models to examine personality change over time. For each domain and facet, we fit the following models, hierarchically: (1) an interceptonly model - a single factor with the loadings of the measurement occasions all fixed to 1 and overall intercept estimated across time points; (2) a linear model - an added slope factor with loadings on this factor fixed to 0-4, indicating linear change; and (3) a quadratic model - an added slope factor with loadings on this factor fixed to $0,1,3,9$, and 16 , indicating quadratic change. Improvements in model fit for the more complex model were taken to indicate meaningful growth in the specified shape (linear or quadratic). When meaningful differences in fit were not found, the simpler model was retained.

We estimated the magnitude of change in $T$-scores $(M=50, S D=10)$, consistent with reporting conventions in this area (e.g., de Haan et al., 2017; Soto et al., 2011). Specifically, we divided the intercept (i.e., mean) estimate for the slope factor (in the augmented model) by the standard deviation of the observed variable (the domain or facet of interest) at the first measurement occasion (age 9), yielding a Cohen's d of the change. This was then converted to a $T$-score $(M=50, S D=10)$ by multiplying the Cohen's d by 10 . Therefore, all $T$-score differences can be interpreted as changes in tenths of age 9 standard deviations (e.g., a 2 T-score unit change from ages 9 to 12 would indicate a change of $\left..20 * \mathrm{SD}_{\text {age } 9}\right)$.

\section{Additional (Exploratory) Analyses}

Though variances in latent slopes and correlations between intercept and slope factors were not a priori specified in the preregistration for this project, we include them here for 
descriptive purposes. These parameters are generally examined as variances in the linear slope factor, with statistically significant variances interpreted as meaningful or reliable individual differences in the rate of change in the domain or facet of interest. Additionally, correlations between latent variables in latent growth models indicate the degree to which change in a trait covaries with the overall level of the trait. Statistically significant correlations are generally interpreted to reflect that different initial trait levels (e.g., high or low Conscientiousness) are related to how much that trait changes over time.

\section{Results}

\section{Deviations from the Preregistration}

In the preregistration for this project (https://osf.io/q48kc), we specified growth analyses across collection wave, but following further examination of studies in this area, we determined that age-grouped (cohort-sequential) analysis would be a more valid approach, as the heterogeneity in age would likely conflate cohort- and age-related effects (e.g., Prinzie \& Onghena, 2014). Analyses across collection wave were conducted to adhere to the preregistration, but they did not differ meaningfully (see https://osf.io/8crwz/ for these results).

\section{Measurement Invariance Analyses}

We first examined whether facets and domains were invariant across age groups/time and gender. Among domains, analyses across cohort/time indicated that Agreeableness and Openness to Experience met criteria for strict invariance, Conscientiousness met criteria for metric invariance, and Neuroticism and Extraversion met criteria for configural invariance. Invariance results for each domain and facet by cohort/time point are summarized in OSF Supplemental Table 2, and all invariance analyses (including those by gender and cohort/time point) are found on the OSF page for this project. No domains achieved less than metric/weak gender invariance 
in more than one cohort/time point. These results indicate that domain-level models pooled across genders can be interpreted.

Analyses across cohort/time indicated that six facets met criteria for strict invariance (Shy, Sociability, Antagonism, Intellect, Openness, and Compliance), two facets met for scalar/strong invariance (Fear and Strong Willed), four met for metric/weak invariance (Positive Emotions, Organized, Achievement Orientation, and Distractible), and three met for configural invariance (Negative Affect, Considerate, and Activity Level). All facets demonstrated at least configural invariance across gender at each time point.

\section{Stability Analyses}

A summary of rank-order stabilities by facet, domain, and time lag can be found in Table 2. Stability was greater than our preregistered prediction of moderate effect sizes for both domains and facets across all time intervals. Domain-level stability from T1-T4 for all ages ranged from $r=.63$ (Agreeableness) to $r=.72$ (Extraversion). Facet-level stability from T1-T4 ranged from $r=.57$ (Antagonism) to $r=.72$ (Sociability). Year-to-year stabilities were substantially higher than these estimates (see Table 2). Steiger tests examining differences in stability coefficients between domains revealed no significant differences. However, Steiger tests for differences between facet stabilities (within each domain) yielded two significant differences: between Sociability $(r=.72,95 \%$ CI $[.64, .77])$ and Positive Emotions $(r=.62,95 \%$ CI $[.53$, $.69] ; z=2.10, p=.035)$ and Sociability and Considerate $(r=.61,95 \%$ CI $[.52, .69] ; z=2.25, p=$ .024). The difference between stabilities for Sociability and Activity Level ( $r=.65,95 \%$ CI [.56, .72]) was not significant $(z=1.71, p=.088)$. These results indicate that Sociability was more stable than two of the three other facets of Extraversion. However, facets within each of the other domains did not show different amounts of stability across the transition to adolescence. 
Table 2

Personality Domain and Facet Rank-Order Stabilities from Ages 9 to 13 Years and Across 3 Years from Intake to Final Follow Up

\begin{tabular}{|c|c|c|c|c|c|}
\hline & $\begin{array}{c}9-10 \\
r[95 \% \mathrm{CI}]\end{array}$ & $\begin{array}{c}10-11 \\
r[95 \% \mathrm{CI}]\end{array}$ & $\begin{array}{c}11-12 \\
r[95 \% \mathrm{CI}]\end{array}$ & $\begin{array}{c}12-13 \\
r[95 \% \mathrm{CI}]\end{array}$ & $\begin{array}{c}\mathrm{T} 1-\mathrm{T} 4 \\
r[95 \% \mathrm{CI}]\end{array}$ \\
\hline \multicolumn{6}{|l|}{ Characteristic } \\
\hline Neuroticism & $.83[.75, .88]$ & $.75[.67, .81]$ & $.77[.71, .82]$ & $.72[.54, .83]$ & $0.69[0.61,0.75]$ \\
\hline Fear & $.79[.70, .86]$ & $.63[.52, .72]$ & $.65[.56, .73]$ & $.64[.46, .77]$ & $0.58[0.48,0.66]$ \\
\hline Negative Affect & $.66[.53, .76]$ & $.72[.63, .79]$ & $.68[.59, .75]$ & $.68[.51, .80]$ & $0.65[0.57,0.72]$ \\
\hline Shy & $.77[.66, .84]$ & $.74[.65, .80]$ & $.74[.67, .80]$ & $.64[.46, .77]$ & $0.67[0.59,0.74]$ \\
\hline Extraversion & $.83[.75, .88]$ & $.85[.80, .89]$ & $.81[.75, .85]$ & $.74[.57, .84]$ & $0.72[0.65,0.78]$ \\
\hline Positive Emotions ${ }^{\mathrm{a}}$ & $.73[.62, .82]$ & $.79[.72, .85]$ & $.78[.72, .83]$ & $.66[.47, .79]$ & $0.62[0.53,0.69]$ \\
\hline Sociable $^{\mathrm{b}}$ & $.81[.72, .87]$ & $.84[.78, .88]$ & $.77[.71, .82]$ & $.72[.55, .83]$ & $0.72[0.64,0.77]$ \\
\hline Considerate & $.69[.57, .79]$ & $.72[.64, .79]$ & $.77[.71, .82]$ & $.69[.51, .81]$ & $0.61[0.52,0.69]$ \\
\hline Activity Level & $.73[.62, .81]$ & $.79[.72, .84]$ & $.72[.64, .78]$ & $.73[.57, .84]$ & $0.65[0.56,0.72]$ \\
\hline Conscientiousness & $.80[.71, .86]$ & $.78[.71, .84]$ & $.84[.80, .88]$ & $.84[.73, .91]$ & $0.68[0.61,0.75]$ \\
\hline Organized & $.77[.66, .84]$ & $.70[.61, .78]$ & $.81[.76, .86]$ & $.81[.69, .88]$ & $0.65[0.56,0.72]$ \\
\hline Achievement Orientation & $.71[.59, .80]$ & $.76[.69, .82]$ & $.79[.72, .83]$ & $.73[.59, .83]$ & $0.60[0.51,0.68]$ \\
\hline Distractible & $.72[.60, .81]$ & $.72[.63, .79]$ & $.74[.67, .80]$ & $.72[.57, .82]$ & $0.63[0.54,0.70]$ \\
\hline Agreeableness & $.66[.53, .77]$ & $.73[.64, .80]$ & $.73[.65, .79]$ & $.74[.58, .85]$ & $0.63[0.54,0.70]$ \\
\hline Antagonism & $.64[.50, .75]$ & $.64[.53, .73]$ & $.61[.52, .70]$ & $.72[.62, .80]$ & $0.57[0.48,0.65]$ \\
\hline Strong Willed & $.58[.42, .70]$ & $.71[.62, .78]$ & $.72[.64, .78]$ & $.73[.63, .81]$ & $0.63[0.54,0.70]$ \\
\hline Openness to Experience & $.82[.74, .88]$ & $.84[.78, .88]$ & $.79[.73, .84]$ & $.72[.54, .83]$ & $0.67[0.60,0.74]$ \\
\hline Intellect & $.84[.76, .89]$ & $.81[.75, .86]$ & $.78[.72, .83]$ & $.72[.62, .80]$ & $0.68[0.60,0.75]$ \\
\hline Openness & $.71[.58, .80]$ & $.76[.69, .82]$ & $.71[.64, .78]$ & $.69[.58, .78]$ & $0.60[0.50,0.67]$ \\
\hline Compliant & $.71[.59, .80]$ & $.76[.68, .82]$ & $.69[.61, .76]$ & $.68[.57, .77]$ & $0.61[0.52,0.68]$ \\
\hline
\end{tabular}

Note. $\mathrm{CI}=$ Confidence Interval

${ }^{a}$ Evidences significant differences between genders; ${ }^{b}$ Evidences significant differences from two of three other facets in the same domain 
Fisher's $r$-to- $z$ tests for stability differences between genders revealed that domain and facet-level stability was also largely the same between boys and girls across domains and facets, with a few exceptions. Tests for differences between genders in domain-level stability yielded a significant difference for Conscientiousness $(z=2.78, p=.005)$, suggesting that girls $(r=.76$, $95 \%$ CI $[.60, .79])$ were more stable on this dimension than boys were $(r=.55,95 \%$ CI $[.40$, .67]). Tests for differences between genders in facet stabilities revealed that girls were significantly more stable on Organized $(r=.72,95 \%$ CI $[.62, .80])$ than boys $(r=.51,95 \% \mathrm{CI}$ $[.36, .64] ; z=2.54, p=.011)$, and that girls were more stable on Achievement Orientation $(r=$ $.68,95 \%$ CI $[.57, .77])$ than boys $(r=.46,95 \%$ CI $[.30, .60] ; z=2.44, p=.015)$. However, this was not the case for the remaining facet of Conscientiousness, Distractible (girls $r=.63,95 \% \mathrm{CI}$ $[.50, .73]$; boys $r=.60,95 \%$ CI $[.46, .71] ; z=0.3 .6, p=.722)$. In summary, facet- and domainlevel stabilities were largely the same between genders; however, girls were more stable than boys on two of three Conscientiousness facets across the transition to adolescence.

Latent growth analyses. Latent growth analyses revealed small to moderate ( $T$-scores $[1,4])$ linear change in 13 of 15 facets and all domains. These results also demonstrated specificity by facet and gender, such that not all facets within each domain changed to the same extent or in the same direction, nor did all facets change to the same extent between genders. A summary of these findings can be found in Table 3, and model-implied changes are illustrated in Figures 1-6. Only 6 of 15 quadratic growth models converged without negative residual variance. Of those models, none significantly improved fit over linear models by all metrics, and therefore, all change reported here is linear. Quadratic growth estimates can be found on the OSF page for this project. Effect sizes interpreted here as "significant" were all within the range of our preregistered effect sizes of interest ( $T$-score differences $[1,4])$. We report all unstandardized 
means, variances, and confidence intervals for growth parameters in Supplemental Table 3 on the OSF page for this project. 
Table 3

Fit Statistics for Personality Domain and Facet Latent Growth Models from Ages 9 to 13 Years - Collapsed Across Gender

\begin{tabular}{|c|c|c|c|c|c|c|c|c|}
\hline Variable & $\begin{array}{c}\text { Retained } \\
\text { Model }\end{array}$ & $\begin{array}{c}\text { T Score } \\
9-13 \\
\end{array}$ & $\Delta \chi^{2}$ & $\Delta \chi^{2} p$ & CFI / TLI & $\begin{array}{l}\text { RMSEA } \\
{[90 \% \mathrm{CI}]}\end{array}$ & SRMR & $\mathrm{AIC} / \mathrm{BIC}$ \\
\hline Neuroticism & Linear & -1 & 12.84 & .005 & $1.0 / 1.0$ & $.02[.00, .06]$ & 0.05 & 2419.5 / 2460.4 \\
\hline Fear & Linear & -2 & 17.47 & $<.001$ & $1.0 / 1.0$ & $.02[.00, .06]$ & 0.06 & $3058.1 / 3099.0$ \\
\hline Negative Affect ${ }^{\mathrm{a}}$ & Linear & -2 & 10.41 & .015 & $1.0 / 1.0$ & $.00[.00, .05]$ & 0.04 & $3203.4 / 3244.31$ \\
\hline Shy & Intercept & 0 & - & - & $1.0 / 1.0$ & $.00[.00, .04]$ & 0.03 & 2864.5 / 2893.1 \\
\hline Extraversion & Linear & -1 & 13.81 & .003 & $1.0 / 1.0$ & $.00[.00, .04]$ & 0.05 & $2082.2 / 2123.1$ \\
\hline Positive Emo. & Linear & -1 & 8.03 & .045 & $1.0 / 1.0$ & $.02[.00, .06]$ & 0.11 & $2757.6 / 2798.5$ \\
\hline Sociable & Linear & -1 & 13.45 & .004 & $1.0 / 1.0$ & $.00[.00, .05]$ & 0.05 & 2752.4 / 2793.2 \\
\hline Considerate $^{\mathrm{a}}$ & Linear & 1 & 19.67 & $<.001$ & $1.0 / 1.0$ & $.00[.00, .05]$ & 0.07 & 2773.4 / 2814.2 \\
\hline Activity Level $^{\mathrm{a}}$ & Linear & -3 & 23.97 & $<.001$ & $.99 / .99$ & $.04[.00, .08]$ & 0.05 & $2961.2 / 3002.1$ \\
\hline Conscientiousness & Linear & 1 & 24.74 & $<.001$ & $.98 / .98$ & $.05[.02, .08]$ & 0.05 & $2601.4 / 2642.3$ \\
\hline Organized & Linear & 1 & 22.93 & $<.001$ & $.99 / .99$ & $.04[.00, .07]$ & 0.06 & $2980.2 / 3021.1$ \\
\hline Achievement Or. & Linear & 1 & 25.14 & $<.001$ & $.98 / .98$ & $.05[.01, .08]$ & 0.06 & $3037.1 / 3078.0$ \\
\hline Distractible (R) & Intercept & 0 & 2.77 & - & $.99 / .99$ & $.04[.00, .07]$ & 0.08 & $3266.1 / 3294.7$ \\
\hline Agreeableness & Linear & 4 & 28.45 & $<.001$ & $1.0 / 1.0$ & $.02[.00, .06]$ & 0.08 & $2553.7 / 2594.5$ \\
\hline Antagonism (R) & Linear & 3 & 19.11 & $<.001$ & $1.0 / 1.0$ & $.00[.00, .05]$ & 0.04 & 2977.3 / 3018.2 \\
\hline Strong Will. (R) & Linear & 3 & 24.48 & $<.001$ & $1.0 / 1.0$ & $.02[.00, .06]$ & 0.08 & $2860.0 / 2900.8$ \\
\hline Openness to Exp. & Linear & -2 & 22.69 & $<.001$ & $1.0 / 1.0$ & $.00[.00, .04]$ & 0.03 & 2183.3 / 2224.1 \\
\hline Intellect & Intercept & 0 & 7.56 & - & $.99 / .99$ & $.04[.00, .07]$ & 0.05 & 2706.6 / 2735.2 \\
\hline Openness & Linear & -4 & 33.8 & $<.001$ & $.99 / .99$ & $.04[.00, .07]$ & 0.05 & $2471.1 / 2511.9$ \\
\hline Compliant & Linear & 3 & 29.72 & $<.001$ & $1.0 / 1.0$ & $.02[.00, .06]$ & 0.09 & 2777.3 / 2818.2 \\
\hline
\end{tabular}

Note. $\mathrm{R}$ = Reverse-Scored; Positive Emo. = Positive Emotions; Achievement Or. = Achievement Orientation; Strong Will. = Strong Willed

${ }^{a}$ Scale met criteria only for configural invariance across age groups; all others met criteria for at least metric/weak invariance 
Figure 1

Personality Domain Model-Implied Growth by Gender from Age 9 to 13

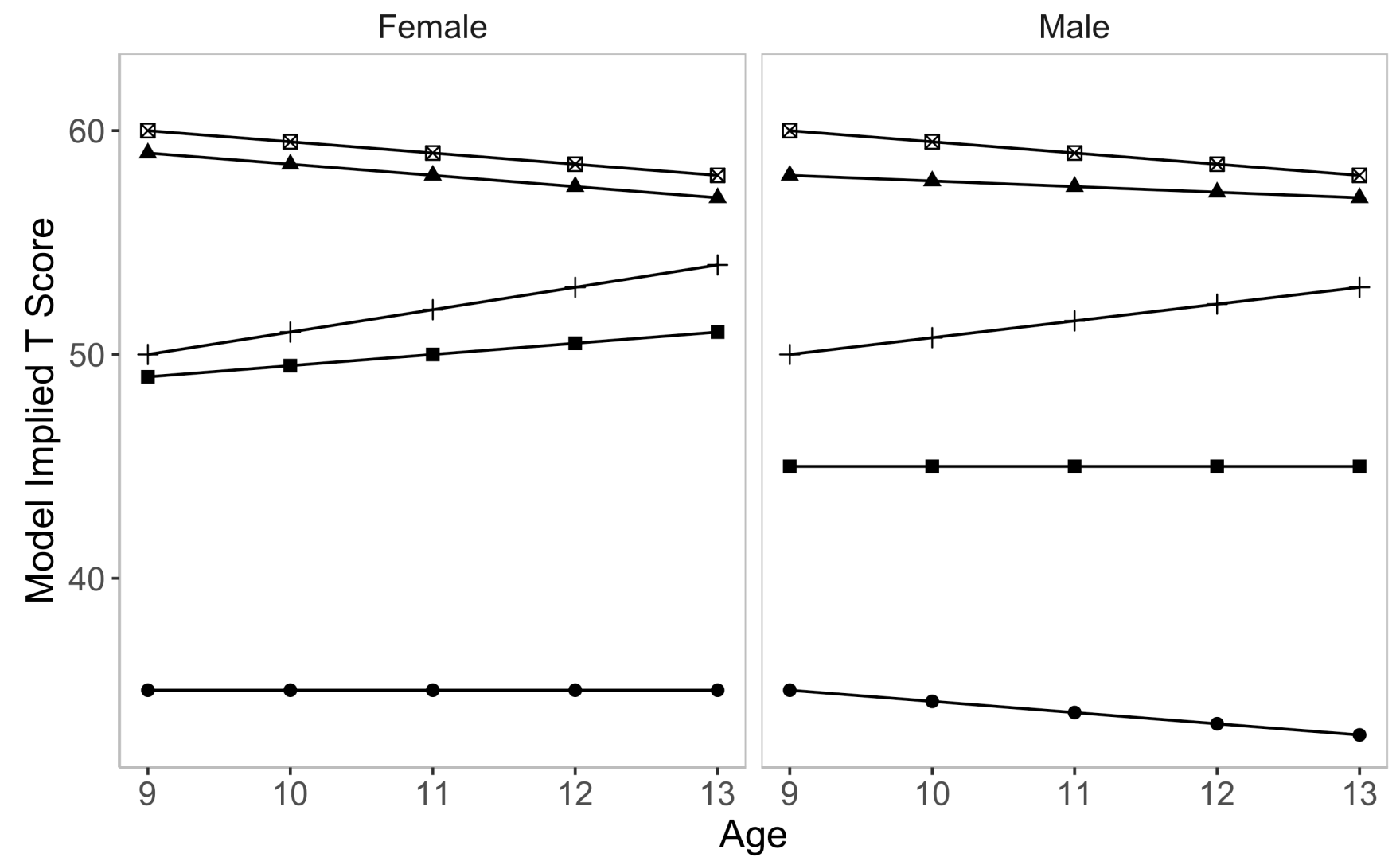

Trait $-\mathrm{N} \Delta \mathrm{E} \| \mathrm{C}+\mathrm{A} \otimes \mathrm{O}$

Note. $\mathrm{N}=$ Neuroticism; $\mathrm{E}=$ Extraversion; $\mathrm{C}=$ Conscientiousness; $\mathrm{A}=$ Agreeableness; $\mathrm{O}=$ Openness to Experience

Contrary to our hypotheses, domain-level Neuroticism showed a small decrease during this period, though only among boys ${ }^{3}$ (a $2 T$-score decrease from 9-13), while girls showed little evidence of change (the intercept-only model was retained). Neuroticism facet-level growth models showed some evidence of facet-level specificity. Fear evidenced average decreases of 2

\footnotetext{
${ }^{3}$ While the male Neuroticism linear model provided somewhat better fit to the data, it should be noted that fit statistics were inconsistent with one another about the linear model's superiority (e.g., the chi-square difference test was nonsignificant $[\mathrm{p}=.081]$, while RMSEA indicated a notable increase in fit [ $\triangle \mathrm{RMSEA}=.03]$ ).
} 
$T$-scores across gender, with no differences between boys and girls that were within the preregistered range. Negative Affect decreased by an average of $2 T$-scores across genders. Separated by gender, Negative Affect showed a linear decrease by $2 T$-scores among boys, but among girls, this model had a latent variable covariance matrix (phi) that was not positive definite (likely due to low coverage in some cells of the matrix resultant of the accelerated longitudinal design). This non-positive definite matrix prevented us from obtaining a reliable estimate of latent change for this facet. Using descriptive statistics only, girls' Negative Affect evidenced a decrease of $.05 \mathrm{SD}_{\mathrm{age} 9}$ (1 $T$-score with rounding) from age 9-13 years. Shy showed no evidence among either gender of linear change across time. 
Figure 2

Neuroticism Facet Model-Implied Change by Gender from Age 9 to 13

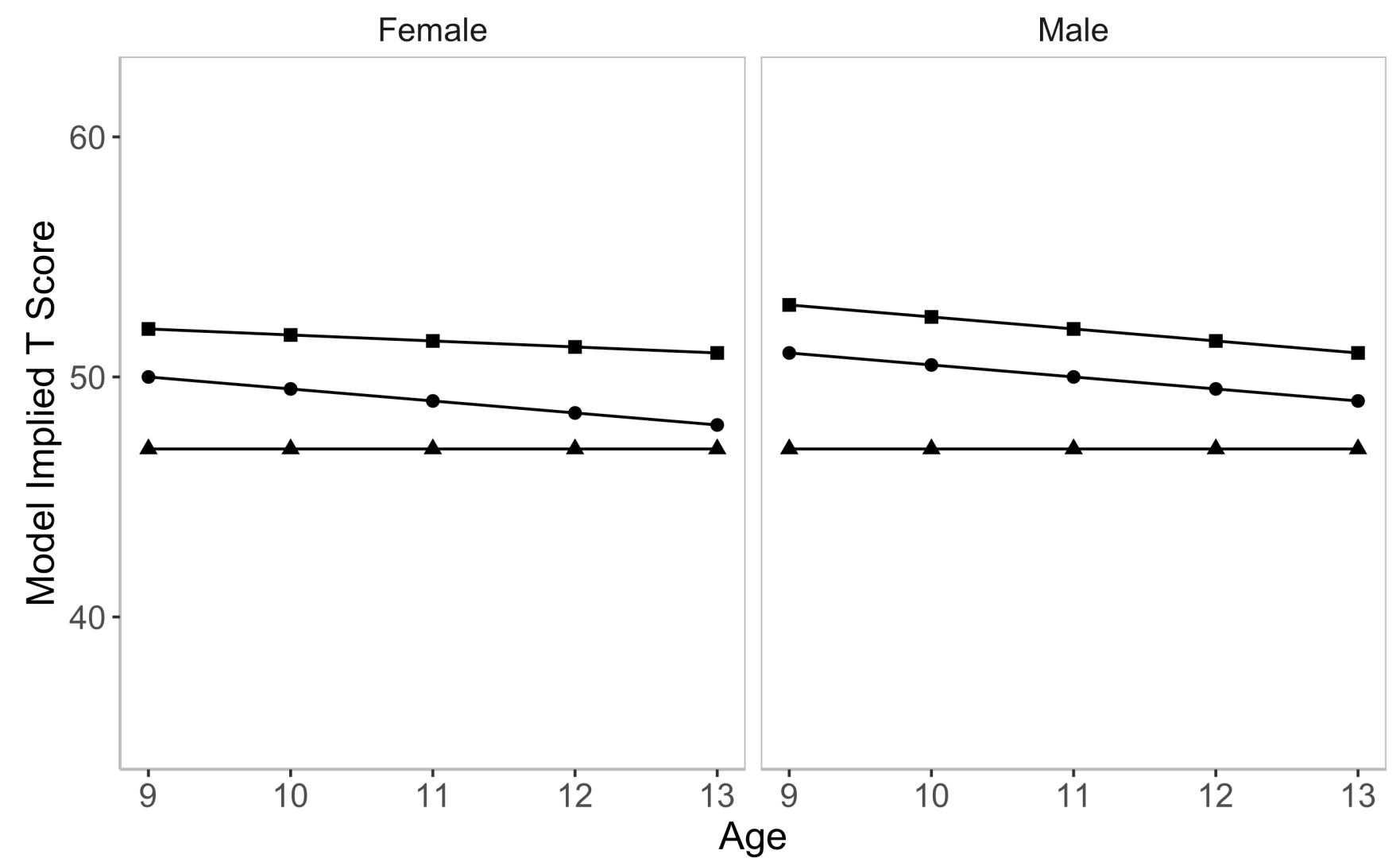

Trait - Fear $\Delta$ Shy - Negative Affect

As hypothesized, Extraversion showed a small degree of overall change, with a decrease of $1 T$-score among boys, and $2 T$-scores among girls. This effect showed small differences between facets, as well. As predicted, Activity Level showed the strongest overall decrease, with boys declining by $3 T$-scores, whereas girls declined by $2 T$-scores. This gender difference was not predicted a priori, however. Sociability also showed specificity by gender, such that girls decreased in Sociability by $2 T$-scores, while boys decreased by $1 T$-score. Positive Emotions decreased slightly overall (1 $T$-score difference), with no differences evident between genders. Contrary to our hypotheses, this degree of change was not greater relative to the overall 
Extraversion domain. In contrast to the rest of Extraversion's facets, Considerate increased, though just among boys ( $T$-score difference of 2$)$, with girls showing no change within the preregistered range.

Figure 3

Extraversion Facet Model-Implied Change by Gender from Age 9 to 13

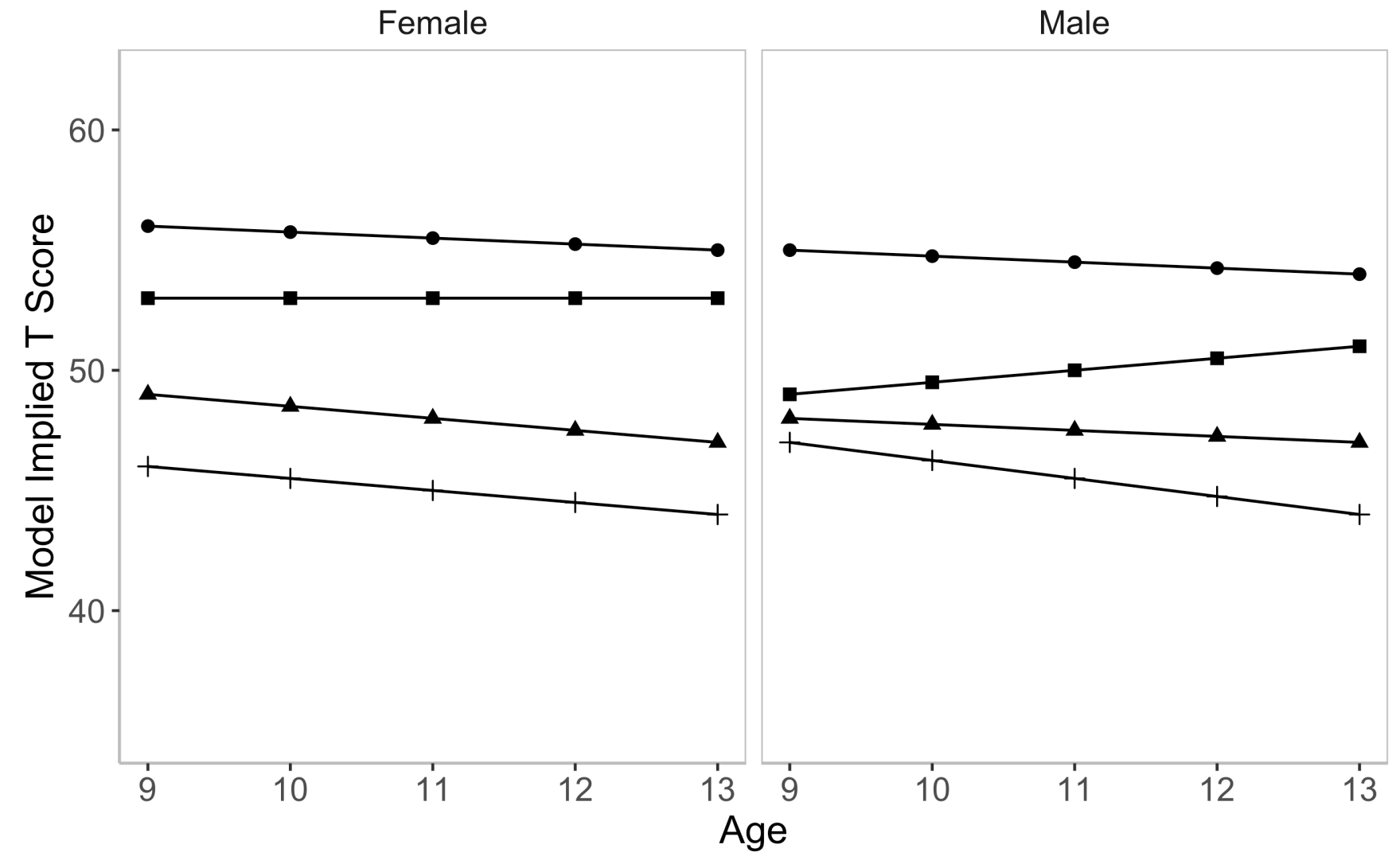

Trait - Positive Emotions $\Delta$ Sociable - Considerate + Activity Level

Note. Positive Emo. = Positive Emotions

Contrary to our hypotheses, Conscientiousness increased overall, though just among girls (2 $T$-score difference), with boys showing no change within the preregistered range. These gender differences were also evident among several Conscientiousness facets. Organized showed a modest increase among girls, with a $2 T$-score difference, while boys showed no linear change. 
Likewise, Achievement Orientation increased by $3 T$-scores among girls, but boys showed no significant change. Distractible showed no overall change (the intercept-only model was retained). Separated by gender, boys showed little evidence of change, and negative latent variable variance prevented us from obtaining a reliable estimate of latent change among girls. Using only descriptive statistics, Distractible (reversed; i.e., attentiveness) evidenced a $2 T$-score increase among girls from age 9 to 13.

Figure 4

Conscientiousness Facet Model-Implied Change by Gender from Age 9 to 13

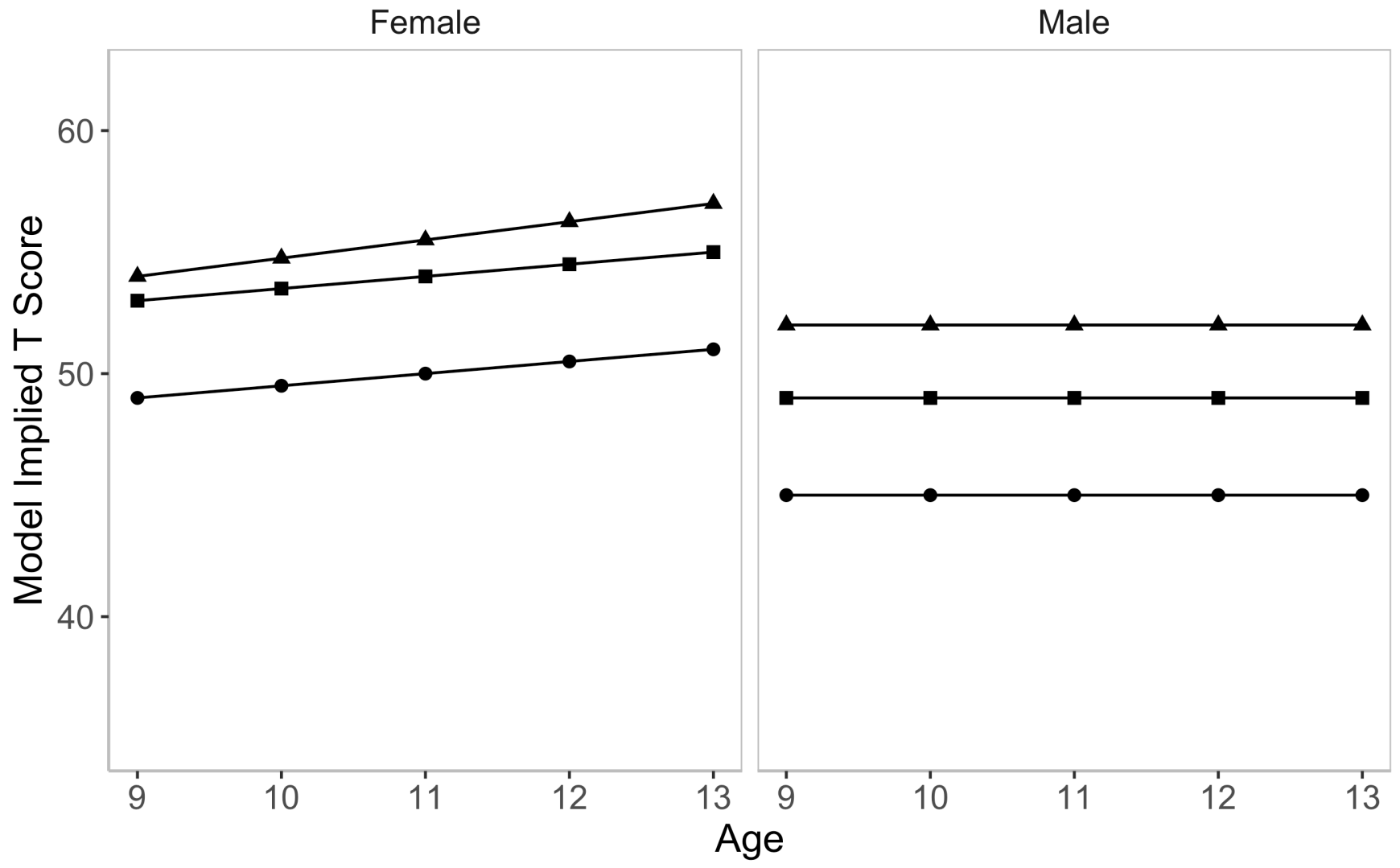

Trait - Organized $\Delta$ Achievement Or. - Distractible (R)

Note. $\mathrm{R}=$ Reverse scored; Achievement Or. = Achievement Orientation 
Contrary to our hypotheses, Agreeableness increased overall, with girls showing slightly more change (4 T-scores) than boys (3 $T$-scores). Facet-level growth models showed some evidence of gender and facet-level specificity. Antagonism (reversed; i.e., gentleness) increased more among boys (3 $T$-score difference) than girls (2 $T$-score difference). Strong Willed (reversed; i.e., meekness or unassertiveness) increased by $2 T$-scores among boys, though the linear model among girls resulted in negative latent variable variance, and thus we were unable to obtain a reliable estimate of latent change among females on this facet. Using descriptive statistics only, females' Strong Willed (reversed) increased by $4 T$-scores from age 9 to 13 years. Results from Compliant facet analyses revealed an overall increase in this dimension across genders, with girls showing a slightly greater rise (4 $T$-score difference) in Compliant relative to boys (3T-score difference). These results are consistent with the overall trajectories of the relevant higher-order traits Conscientiousness and Agreeableness, factors on which this facet cross-loads in the ICID-S validation study (Deal et al., 2007). 
Figure 5

Agreeableness Facet Model-Implied Change by Gender from Age 9 to 13

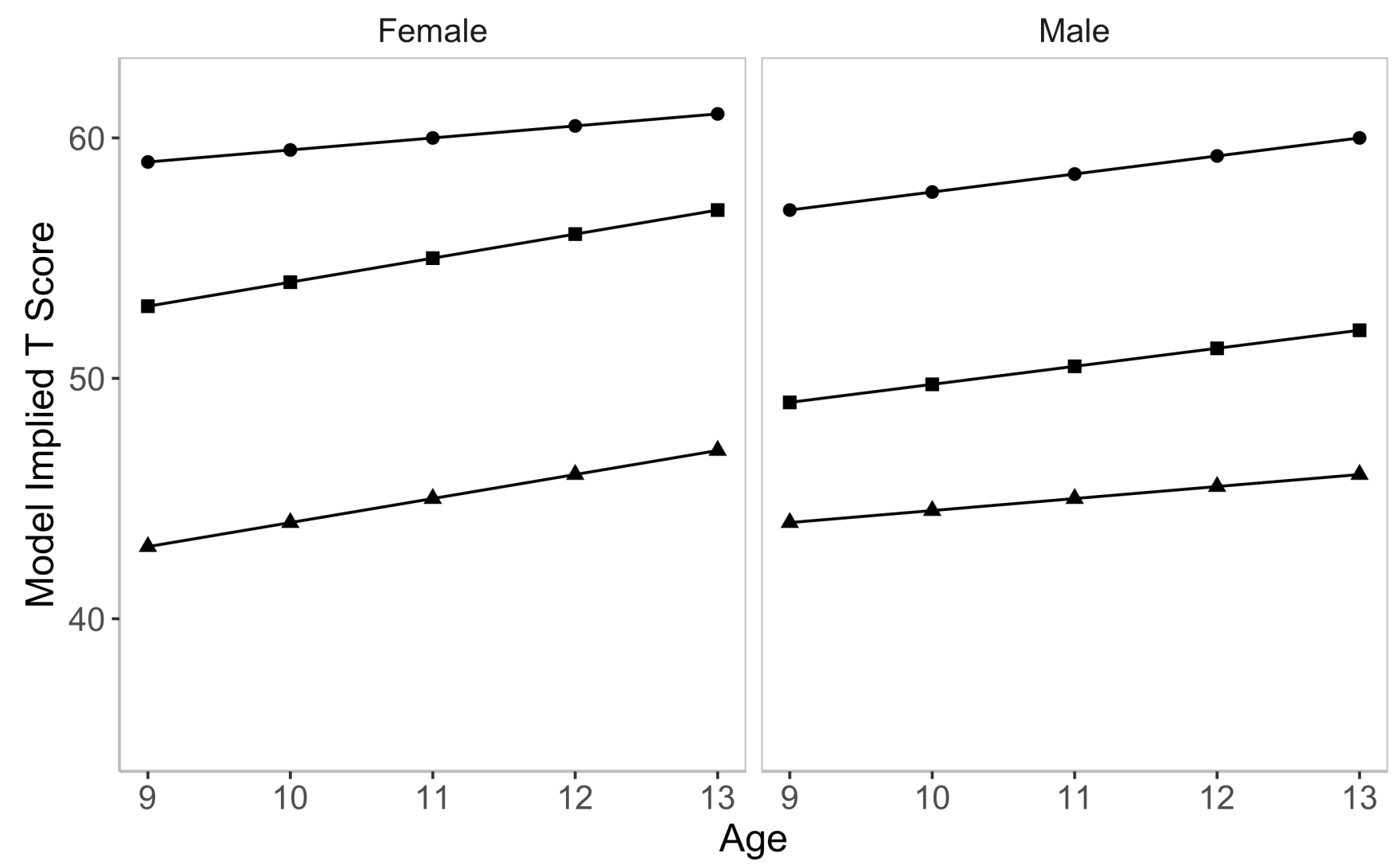

Trait - Antagonism (R) \ Strong Willed (R) - Compliant

Note. Despite that in the Deal et al. (2007) scoring, Compliance has a cross-loading on Conscientiousness in addition to Agreeableness, it is included here due to its greater similarity in trajectory with other facets of Agreeableness.

$\mathrm{R}=$ Reverse scored

As hypothesized, Openness to Experience showed a small overall decrease over this period, with a $T$-score difference of 2 that was consistent among both girls and boys. Facet-level growth models showed evidence of strong facet-level specificity. Intellect showed no evidence of change over this period among either boys or girls. However, the facet Openness decreased 
across both genders, with girls showing slightly more change (4 $T$-score difference) than boys ( 3 $T$-score difference).

Figure 6

Openness to Experience Facet Model-Implied Change by Gender from Age 9 to 13

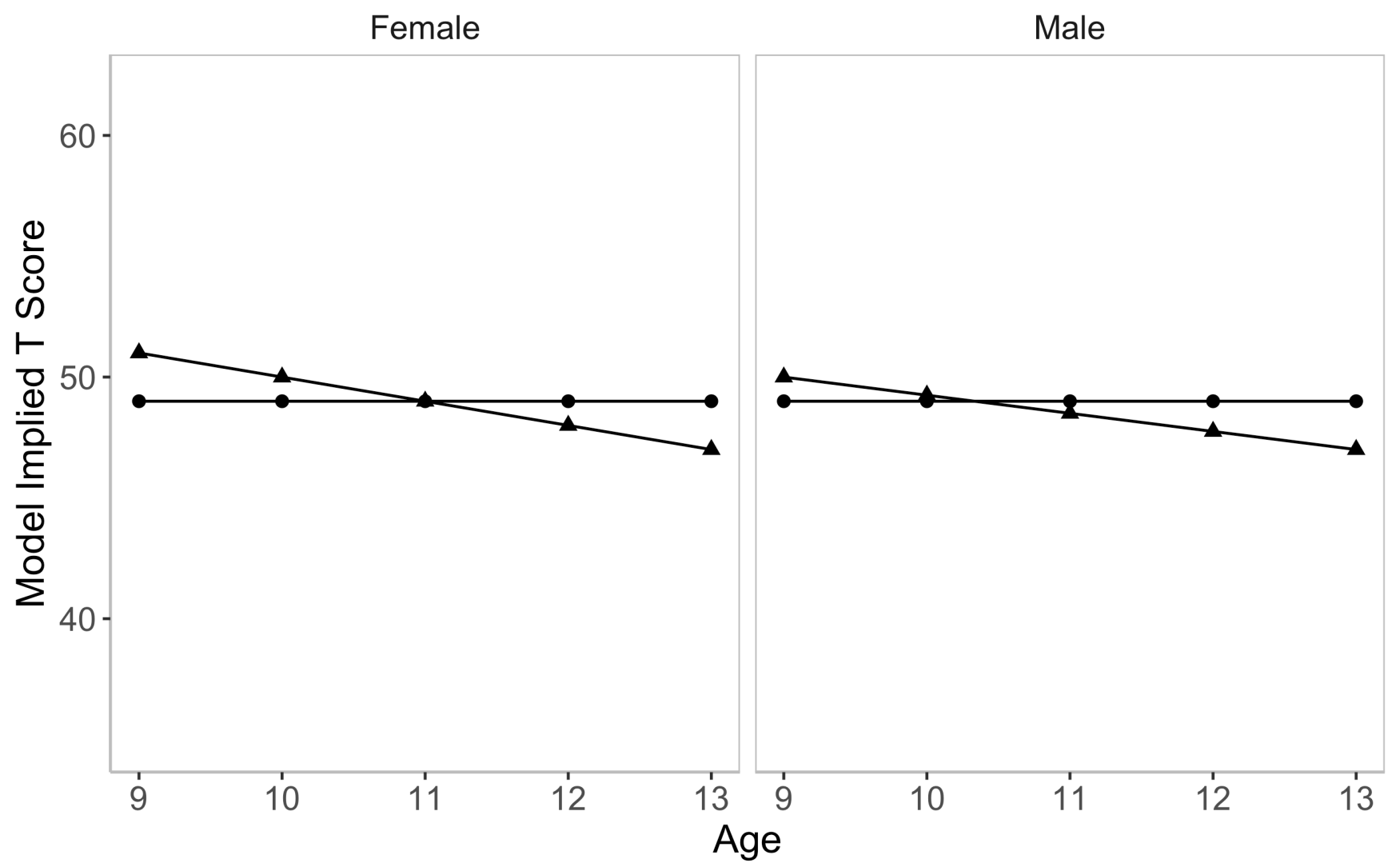

Trait - Intellect $\Delta$ Openness

Additional (exploratory) analyses. All domains demonstrated significant linear slope factor variance $(p<.05)$, indicating that there are significant individual differences in the degree of change shown by individuals in Neuroticism, Extraversion, Conscientiousness, Agreeableness, and Openness to Experience.

Among facets of Neuroticism, only Fear showed significant variance in the linear slope factor, while Negative Affect and Shy did not. This indicates that there was greater variation 
between individuals in the degree to which they changed in fearfulness, more so than for change in irritable negative emotionality and shyness. All facets of Extraversion and Openness to Experience showed significant linear slope factor variance, indicating that there was substantial variation between individuals in their degree of change for all facets in these domains.

Conscientiousness facets Organized and Achievement Orientation also showed significant slope variance, while Distractible did not. This suggests that there was greater variation between individuals' Organized and Achievement Orientation trajectories, more so than for change in Distractible. Finally, among facets of Agreeableness, Antagonism showed significant linear factor variance, while Strong Willed did not. This indicates that individuals varied more in Antagonism than Strong Willed trajectories. Compliant did not demonstrate significant variance in the linear slope factor.

In the analysis of correlations between latent slope and intercept factors, we found that Openness to Experience $(r=-.40, p=.006)$, Fear $(r=-.45, p=.008)$, Sociability $(r=-.34, p=$ $.034)$, Considerate $(r=-.51, p=.001)$, and facet-level Openness $(r=-.35, p=.041)$ showed significant relationships between their overall levels of the trait and the degree to which they changed in that trait. As these correlations were negative, they all indicated that the higher an individual's baseline level of the trait, the less change they tended to show across time.

\section{Discussion}

In summary, the present study demonstrates that the developmental trends of parentreported facet-level traits show a high degree of within-domain consistency; however, some facets also show a notable degree of deviation from this pattern. In our analyses, rank-order stability (i.e., correlations over time) did not vary significantly between facets within each Five Factor Model trait domain apart from Sociability, which was significantly more stable than two 
of three other facets of Extraversion. However, we saw significant variability between facets in mean-level (i.e., age-related) changes; this was evident specifically within domains of ICID Neuroticism, Extraversion, and Openness to Experience. We also found some evidence of gender differences in stabilities for Conscientiousness and in mean-level trends for facets of Neuroticism, Extraversion, and Conscientiousness. Rank-order stability of parent-reported facetand domain-level traits was large and mean-level changes were small. Contrary to our predictions, we found more evidence of maturity than disruption in domain and facet mean-level trends in the transition from childhood to early adolescence. Consistent with our predictions, however, we found evidence of some personality disruption in facet-level Openness to Experience. Overall, we hope that the results of the present study may spur future research examining the contexts in which facets (relative to domains) may be useful in describing personality development and identifying the exact timing of personality disruption in adolescence.

\section{Rank-Order Stability}

We hypothesized that personality stability would be moderate in this age range; however, our results showed large to very large effects for domain- and facet-level stability, with stability estimates between the first (T1) and last (T4) time points (across 3 to 4 years) ranging from $r=$ $[.57, .72]$ and year-to-year stabilities including even higher estimates. There are several possible explanations for the differences between our expected and observed magnitudes of trait stability. One likely interpretation of these results is that the stability we hypothesized was an underestimate, as it was partially based on prior studies in this area with greater lags between follow up assessments (e.g., 3 years in De Fruyt et al., 2006 vs. 1 year in the present study). As demonstrated in large meta-analyses and captured by the cumulative continuity principle, we 
also expected stability of child personality to be lower than is typically found in adults (Roberts \& DelVecchio, 2000). However, we observed no evidence of increases in parent-reported personality stability across years 9-13, nor did T1- to-T4 stability estimates differ substantially from those found among adult samples. As it has been observed that personality stability is greater with more immediate follow up assessments (Hampson \& Goldberg, 2006), the high degree of stability evidenced in our study may be a result of our relatively more frequent measurement of personality or the stronger psychometric properties of parent-informant ratings of personality relative to self-ratings in children (Soto et al., 2008; Tackett, 2011).

An alternative interpretation of these results is that our measure or informants used to assess personality may capture more stable personality variance over time than those of previous studies. As many early longitudinal studies of child personality used adult assessments that had been "adapted down" (rather than initially validated for) younger age groups (e.g., NEO PI-R; McCrae et al., 2002), these prior studies may have underestimated the true rank-order stability of child personality in the period of late childhood or early adolescence by excluding developmentally appropriate instantiations of traits. In accordance with this observation, our results are more similar to prior research finding facet stability estimates of $r \geq .60$ using only empirically derived child personality inventories (e.g., the Hierarchical Personality Inventory for Children; De Fruyt et al., 2006; de Haan et al., 2017) versus those using adapted adult measures (e.g., NEO PI-R). It is also possible that we observed higher stability in the present study because we relied on parent informants (rather than youths themselves). Some may argue that parents' perceptions may be less sensitive to shorter-term or year-to-year personality changes than child self-reports are. However, previous research has not found differential stability for youth- versus parent-reported domain-level traits except for neuroticism (which shows lower stability for self- 
report; Luan et al., 2017). Further, prior research also demonstrates that different informants capture valid and overlapping, but distinct aspects of individual differences (e.g., Luan et al., 2017; Soto et al., 2008; Tackett, 2011; Vazire, 2010). Therefore, neither parent- nor youthreports are more intrinsically valid indicators of latent personality development. Our results converge on the point that stability is high at least for parent-reported domain- and facet-level personality traits, even in the pre-teen years, and that many references to lower trait stability for child personality (relative to adults) found in the broader literature must be interpreted in the context of the informants, measures, and time gaps over which they are assessed.

\section{Evidence for Maturity in the Preadolescent Period}

The maturity principle states that with age, individuals continuously increase in socially desirable traits, including conscientiousness and agreeableness and decrease in socially undesirable traits, including neuroticism. We observed substantial evidence for this process in the transition to adolescence. However, maturity patterns in our sample were not entirely consistent between genders, nor between facets within higher-order ICID Neuroticism, Extraversion, Conscientiousness, and Agreeableness domains. Generally, boys showed more maturity in Negative Affect (a facet of N), which indexes irritability and externally directed negative emotions and in Considerate (a facet of E), which indexes interpersonal sensitivity and other prosocial aspects of Extraversion. As has been seen in prior studies (e.g., Soto et al., 2011), girls' initial Extraversion facet ratings were slightly higher than boys' with the exception of Activity Level, on which boys were slightly higher than girls. Changes in Extraversion facets (among both boys and girls) therefore resulted in an overall narrowing of the Extraversion gap between boys and girls. Girls showed substantially more maturity in all facets of Conscientiousness. This gender difference was particularly evident for the Achievement 
Orientation facet. Both boys and girls evidenced decreases in Fearful/Insecure (a facet of N), increases across Agreeableness facets, and Compliant, a related interstitial facet indexing both Agreeableness and Conscientiousness (Deal et al., 2007).

Gender differences in maturational patterns of conscientiousness may be particularly important for this developmental stage. In the period under study here (age 9-13), the transition to high school is an upcoming major role change that will present new, important academic challenges with potentially far-reaching consequences. As Canadian high school begins at grade nine (around 14 years), children in the present sample were on the cusp of this transition. In these results, we observed that girls increased in all relevant facets of conscientiousness, which might be interpreted as "gearing up" for these future challenges. In contrast, boys did not appear to do so. Previous cross-sectional studies have identified that gender differences in self-regulatory traits are overlapping with achievement gaps in high school (with girls showing both higher achievement and self-discipline, on average; De Fruyt et al., 2008). While there is evidence that change in conscientiousness is correlated with change in achievement behaviors (e.g., time spent on homework; Bleidorn, 2012), it has yet to be determined if gender-related academic gaps codevelop with or follow from personality maturational gaps. These results suggest that there may be important differences in personality maturation between boys and girls in the preadolescent period; the implications of these differences are in need of further study.

\section{Evidence for Disruption in the Preadolescent Period}

Contrary to our expectations, there was evidence of only a small amount of personality disruption in the present study. In line with our hypotheses, however, we observed decreases in Openness, a facet of Openness to Experience capturing curiosity and imagination. Interestingly, though this pattern is now well-documented across a variety of studies (e.g., De Fruyt et al., 
2006; Luan et al., 2017; Soto et al., 2011), few potential explanations for these findings have been put forth. Perhaps the only reasoning that has been advocated is that youth begin to experience more social pressure to conform, increased social sensitivity, and decreased resistance to peer influence in the early teenage years, processes that may discourage individual expression and nonnormative behavior (Brechwald \& Prinstein, 2011; Sumter et al., 2009). However, youth self-reported openness did not show the same downward trend in a prior study (Luan et al., 2017), possibly indicating that parents and youth may either have access to different information, or their definitions of imagination and creativity may differ in the teenage years. As openness to experience in childhood is a largely understudied area, much remains to be discovered about the function and significance of openness decline in this developmental period.

We did not replicate some prior work (e.g., De Haan et al., 2017; Soto et al., 2011) showing temporary regression in personality maturity (i.e., disruption) in the transition to adolescence for traits other than openness. Specifically, within the neuroticism domain, Soto and colleagues (2011) found that in a comparison of age groups from middle childhood to adolescence, older girls tended to be more neurotic across both anxiety and depression facets, while boys showed no differences. In the present study, though facets within neuroticism showed no consistent pattern of change, there was some evidence that both boys and girls decreased in ICID Fear and boys decreased in ICID Negative Affect. This measure, however, does not capture any facets related to depression or sadness, and thus, this lack of replication could be due in part to differences in the measures used. However, our results were in line with the findings of De Haan and colleagues (2017) showing that while fearfulness may increase throughout the early and middle childhood period, maturation in neuroticism may, in fact, resume around the transition to adolescence (e.g., age 10-11 years). Additionally, our findings converge with 
previous cross-sectional evidence of a similar pattern using the ICID measure (Slobodskaya \& Akhmetova, 2010).

Within the conscientiousness domain, multiple studies have previously found decreases in conscientiousness across similar age periods to the one in the present study (e.g., approximately 10-15 years; De Fruyt et al., 2006; Soto et al., 2011). However, we found increases in all conscientiousness facets only for girls, whereas boys showed no change. These results do, however, partially replicate other prior research showing no change in conscientiousness over this period (though gender differences were not reported; Roberts et al., 2006) or small increases in one cross-sectional study using the ICID, albeit over only partially overlapping age ranges to the one in the present study (age groups 11-14 vs. 15-18 years; Slobodskaya \& Akhmetova, 2010).

In the domain of agreeableness, prior findings are even more heterogenous. While in their cross-sectional study, Soto and colleagues (2011) found decreases in agreeableness across the transition to adolescence, several other researchers have demonstrated little to no longitudinal change in agreeableness from middle childhood to adolescence (De Fruyt et al., 2006; Roberts et al., 2006). Further, other research has demonstrated differences between facets in the directions and magnitude of agreeableness change. de Haan and colleagues (2017) found declines in agreeableness across most facets captured by the Hierarchical Personality Inventory for Children, aside from Altruism, which increased in girls across the period under study (age 9-13) and Irritability, which did not change for girls or boys (de Haan et al., 2017). In the present study, we found increases in agreeableness across gender and facets, which is largely in contrast to prior studies. 
Although we cannot determine precisely why our study failed to replicate some of these prior findings, multiple possible explanations merit testing in future research. First, the differences in the lower-order facet structure of various personality inventories used in prior studies on age-related personality change make comparisons between our findings and prior research particularly difficult. While domain-level changes may be relatively more comparable between different inventories given their higher bandwidth, facets covering more narrow, specific sets of behaviors may not directly translate between studies. Second, the different age bands and time gaps between measurements in prior research on this topic is a further barrier to understanding non-replications between studies. Greater fidelity in measuring longitudinal change would allow future researchers to better (though not perfectly) tease apart null effects due to developmental timing (i.e., if they missed a critical window), measurement issues, and other possible explanations (e.g., Type I \& II error). While this non-replication might simply indicate that personality disruption occurs later in adolescence than we measured here (an interpretation in line with some prior findings; Slobodskaya \& Akhmetova, 2010), more longitudinal research is required to test this theory in the future. This future work will be most helpful in identifying the timing of personality shifts if it incorporates frequent assessments over critical intervals such as the period from preadolescence to young adulthood. Overall, empirical data of this nature are so scarce that differences across studies should not yet be taken as evidence of "non-replication" so much as additional data points to contribute to a small but hopefully growing evidence base for personality facet development in children.

The present findings on developmental trends in low-bandwidth traits may also help researchers understand what we are measuring when we measure personality in youth relative to adults. In adult personality models, agreeableness is indicated by both the presence of prosocial 
tendencies (e.g., is warm, is kind) as well as the absence of antisocial tendencies (e.g., is rude, manipulates others). Adult extraversion, on the other hand, accounts for aspects of social dominance, gregariousness, activity, and positive emotions (e.g., Costa \& McCrae, 1992; Soto \& John, 2017). However, studies of the structure of child personality sometimes find that that prosocial tendencies in children converge more with general sociability (i.e., extraversion), while antisocial tendencies sometimes form a separate (dis)agreeableness trait that overlaps heavily with negative affectivity (De Pauw et al., 2009; Tackett et al., 2012). In the present study, Considerate (a facet of Extraversion in the ICID model) is perhaps the facet-level trait most indicative of prosocial tendencies, including items such as "My child is... thoughtful of others" and "... sensitive to others' feelings" (Deal et al., 2007). We observed that Considerate meanlevel changes were much more similar to those of Agreeableness facets than to those of other Extraversion facets. Therefore, this might suggest that by middle childhood, agreeableness starts to look and function more like its adult counterpart than its childhood version: it may include both the inhibition of socially negative behaviors and the activation of socially positive ones. This finding is corroborated by psychometric research in child personality showing that personality structure in adolescents is virtually identical to that of adults (Tackett et al., 2012). In summary, the early adolescent period appears to be a critical one for personality development both in the context of overall trait levels (i.e., age-related mean-level changes) and in how traits are related to one another within individuals (i.e., age-related structural differences). However, future research is needed to determine the extent to which these two forms of change might be linked through various developmental mechanisms.

\section{Future Directions: Precursors and Outcomes}


Although study of the stability and change answers the question of "how" personality develops across the lifespan, the question of "why" personality change occurs requires further investigation regarding its precursors and outcomes. Experimental causal study in this area is not possible or ethical; however, precursors of personality change may be identified by continuously tracking developmental events in conjunction with individual differences. Puberty, for example, is a major biological process occurring during the time period under study here (age 9-13), and it involves both major neural and peripheral biological shifts. Puberty is also directly implicated in shifts in youth social dynamics (e.g., the development of romantic and sexual relationships; Baams et al., 2015). At the average level, the timing of these biological and social shifts may appear to coincide with personality changes, however, pubertal timing and its effects differ widely by individual and by gender (e.g., Mendle et al., 2007). Outside of biological effects, environmental influences such as stressful life events have been likewise implicated as predictors of personality change in youth (e.g., Laceulle et al., 2012). Therefore, future longitudinal studies must continuously assess both personality and relevant indicators of biological, cognitive, and social maturation in the same individuals during critical periods to make inferences about the mechanisms of personality change in the early adolescent period. Prior cross-sectional, but genetically-informed research has found unique genetic contributions to facet-level personality traits (Jang et al., 1998), though further studies that examine developmental precursors as they may (or may not) differentiate the trajectories of personality facets are needed. These study designs will allow for more direct testing of whether and how developmental events such as puberty or life events temporally predict individual personality change.

While identifying processes that may foreshadow or underlie personality development is clearly necessary to move closer to an understanding of causality, an equally important goal is to 
better understand potential real-world outcomes associated with child personality change. For example, the transition to adolescence is a critical period for the development of anxiety and depression (Costello et al., 2003). Cross-sectional research on facet-level traits indicates that subordinate factors of extraversion may show unique associations with internalizing psychopathology (Watson et al., 2015). These studies indicate that facets related to communion (including sociability, activity, and positive affect) tend to show strong negative relationships with depression, anxiety, and externalizing pathology, while facets related to agency (including social dominance and sensation-seeking) are unrelated to internalizing and in fact, positively associated with externalizing psychopathology (Watson et al., 2019). Therefore, the facetspecific patterns of development in Extraversion seen in the present study may merit further scrutiny vis-à-vis their connection to the development of both internalizing and externalizing disorders. However, if facets do not offer incremental prediction in longitudinal examinations of personality and life outcomes, this would suggest that high-bandwidth, domain-level personality measurement may be preferable for characterizing these consequential psychological processes. Future longitudinal studies could incorporate continuous assessment of both personality and relevant academic, health, and social outcomes to facilitate an examination of both codevelopment and potential time-lagged associations between personality facets and domains and life outcomes. A full understanding of why personality change occurs in the adolescent period will incorporate both precursors and outcomes associated with these developmental shifts.

\section{Limitations \& Constraints on Generality}

For methodological, statistical, and practical purposes, the current investigation used only mothers' reports of child personality. Youth self-report questionnaires were not collected during the first and second waves due to substantial issues in the reliability and validity of child self- 
reports of personality and related constructs in ages below 11-12 years (see De Los Reyes \& Kazdin, 2005; Soto et al., 2008). Data collection from a second caregiver (which in most cases was the father) was added to the study protocol after the first wave was underway and was not repeated during the fourth wave, thereby limiting our ability to replicate the current analyses with other informants. Nevertheless, use of mothers' reports of child personality has notable advantages, including greater overlap with reports obtained from unacquainted observers (vs. father reports; Tackett et al., 2016). Moreover, use of female caregiver reports enhances the consistency of this study with prior research findings and clinical practice, which have largely been based on mothers' ratings of children's functioning (De Los Reyes \& Kazdin, 2005; Duhig et al., 2006). Further, adolescence is a time in which youth distance themselves somewhat from family relationships and invest much more in peer relationships (Allen et al., 1994; Steinberg \& Sheffield Morris, 2001), and therefore, parents likely do not have access to complete information about their child's thoughts, feelings, and behaviors across a wider variety of situations outside the home. This interpretation is corroborated by findings that parent- and youth-reports are more discrepant for events that are youth-specific, rather than family-level events (Kushner \& Tackett, 2017). Future research would benefit from the incorporation of multiple informants of youth personality.

The present study was conducted with a community sample of predominantly Caucasian youth in a major urban center in Canada. Our sample was relatively educated, with $87 \%$ of families reporting a postsecondary degree or diploma (vs. 54\% of the most recent Canadian census reporting college or university education; Statistics Canada, 2017). While there was some representation of families across income quintiles, our sample also contained a slightly disproportionate amount of high-income families (35\% vs. 9-14\% in other income sextiles; see 
Table 1). Further, we did not explicitly recruit youth with clinically significant levels of psychopathology, and youth with neurodevelopmental conditions and psychotic disorders were excluded from the study. Based on prior research, we might expect similar patterns of personality development to appear in a variety of clinical and social groups; however, without further replication and extension, we cannot claim that these findings should generalize to populations beyond which the current sample was drawn. In addition, we do not necessarily expect that the same patterns of personality development described here would generalize to youth reports of personality, given prior evidence that youth and parent reports diverge in this age group (Luan et al., 2017). Finally, developmental trajectories of lower-order traits may differ to some degree when using personality measures other than the ICID, as there is little consensus on the lowerorder trait structure of personality (Brandes \& Tackett, 2019; Tackett et al., 2013). Although some lower-order traits may share the same name between two instruments (e.g., "Depression" from clinical vs. general personality scales), and although item overlap between these scales may be substantial at times, items may also differ meaningfully. Therefore, we strongly advocate that future researchers examine item-level content when developing their hypotheses and interpreting results regarding mean-level changes in lower-order personality traits.

\section{Conclusions}

The present study advances our knowledge of child personality development by homing in on fine-grained (facet-level) approaches to measuring personality through the middle childhood period in a moderately sized sample assessed over four annual waves of data collection. Results indicated that parent reported facet- and domain-level personality traits were remarkably stable from age 9-13 years. We found that facets within each Five Factor Model domain evidenced largely similar patterns in mean-level changes in this age group, though there 
were some notable exceptions to this. These unique facet developmental patterns may suggest that there is a need for further interrogation of the additional information that facets (particularly within the domains of neuroticism, extraversion, and openness) may offer about personality development. Further, we found that boys and girls differed in some, but not all, mean-level trait changes in the transition to adolescence. Overall, our results show that children's personality matured to a small degree over the middle childhood period among self-regulatory facets that cross-cut higher-order domains, with disruption only evident among a single facet of openness to experience. These results provide more support for a continuation of personality maturity in the pre-adolescent period than they do for the disruption hypothesis, at least when measured via parent report. We recommend that future personality researchers consider incorporating alternative levels of the personality hierarchy to further interrogate the construct validity and developmental dynamics of narrowband personality traits. 


\section{References}

Allen, J. P., Hauser, S. T., Bell, K. L., \& O’Connor, T. G. (1994). Longitudinal assessment of autonomy and relatedness in adolescent-family interactions as predictors of adolescent ego development and self-esteem. Child Development, 65(1), 179-194.

Baams, L., Dubas, J. S., Overbeek, G., \& van Aken, M. A. G. (2015). Transitions in body and behavior: A meta-analytic study on the relationship between pubertal development and adolescent sexual behavior. Journal of Adolescent Health, 56(6), 586-598. https://doi.org/10.1016/j.jadohealth.2014.11.019

Beaujean, A. A. (2012). BaylorEdPsych: R Package for Baylor University Educational Psychology (0.5) [R].

Bleidorn, W. (2012). Hitting the road to adulthood: Short-term personality development during a major life transition. Personality and Social Psychology Bulletin, 38(12), 1594-1608. https://doi.org/10.1177/0146167212456707

Bleidorn, W., Kandler, C., Riemann, R., Angleitner, A., \& Spinath, F. M. (2009). Patterns and sources of adult personality development: Growth curve analyses of the NEO PI-R scales in a longitudinal twin study. Journal of Personality and Social Psychology, 97(1), 142155. https://doi.org/10.1037/a0015434

Bleidorn, W., Klimstra, T. A., Denissen, J. J. A., Rentfrow, P. J., Potter, J., \& Gosling, S. D. (2013). Personality maturation around the world: A cross-cultural examination of socialinvestment theory. Psychological Science, 24(12), 2530-2540. https://doi.org/10.1177/0956797613498396

Brandes, C. M., Herzhoff, K., Smack, A. J., \& Tackett, J. L. (2019). The p factor and the $n$ factor: Associations between the general factors of psychopathology and neuroticism in 
children. Clinical Psychological Science, 7(6), 1266-1284.

https://doi.org/10.1177/2167702619859332

Brandes, C. M., \& Tackett, J. L. (2019). Contextualizing neuroticism in the Hierarchical Taxonomy of Psychopathology. Journal of Research in Personality, 81, 238-245. https://doi.org/10.1016/j.jrp.2019.06.007

Brechwald, W. A., \& Prinstein, M. J. (2011). Beyond homophily: A decade of advances in understanding peer influence processes. Journal of Research on Adolescence, 21(1), 166179. https://doi.org/10.1111/j.1532-7795.2010.00721.x

Browne, M. W., \& Cudeck, R. (1992). Alternative ways of assessing model fit. Sociological Methods and Research, 21(2), 230-258.

Caspi, A., Roberts, B. W., \& Shiner, R. L. (2005). Personality development: Stability and change. Annual Review of Psychology, 56(1), 453-484. https://doi.org/10.1146/annurev.psych.55.090902.141913

Costa, P. T., \& McCrae, R. R. (1992). Revised NEO personality inventory (NEO PI-R) and NEO five-factor inventory (NEO-FFI): Professional manual. Psychological Assessment Resources, Inc.

Costello, E. J., Mustillo, S., Erkanli, A., Keeler, G., \& Angold, A. (2003). Prevalence and development of psychiatric disorders in childhood and adolescence. Archives of General Psychiatry, 60(8), 837. https://doi.org/10.1001/archpsyc.60.8.837

Cronbach, L. J., \& Gleser, G. C. (1965). Psychological Tests and Personnel Decisions. University of Illinois Press.

De Fruyt, F., Bartels, M., Van Leeuwen, K. G., De Clercq, B., Decuyper, M., \& Mervielde, I. (2006). Five types of personality continuity in childhood and adolescence. Journal of 
Personality and Social Psychology, 91(3), 538-552. https://doi.org/10.1037/00223514.91 .3 .538

De Fruyt, F., Van Leeuwen, K., De Bolle, M., \& De Clercq, B. (2008). Sex differences in school performance as a function of conscientiousness, imagination and the mediating role of problem behaviour. European Journal of Personality, 22(3), 167-184. https://doi.org/10.1002/per.675

de Haan, A., De Pauw, S., van den Akker, A., Deković, M., \& Prinzie, P. (2017). Long-term developmental changes in children's lower-order Big Five personality facets. Journal of Personality, 85(5), 616-631. https://doi.org/10.1111/jopy.12265

De Los Reyes, A., \& Kazdin, A. E. (2005). Informant discrepancies in the assessment of childhood psychopathology: A critical review, theoretical Framework, and recommendations for further study. Psychological Bulletin, 131(4), 483-509. https://doi.org/10.1037/0033-2909.131.4.483

De Pauw, S. S. W. (2017). Childhood Personality and Temperament. In T. A. Widiger (Ed.), The Oxford Handbook of the Five Factor Model (pp. 243-280). Oxford University Press.

De Pauw, S. S. W., Mervielde, I., \& Van Leeuwen, K. G. (2009). How are traits related to problem behavior in Preschoolers? Similarities and contrasts between temperament and personality. Journal of Abnormal Child Psychology, 37(3), 309-325. https://doi.org/10.1007/s10802-008-9290-0

Deal, J. E., Halverson, C. F., Martin, R. P., Victor, J. B., \& Baker, S. R. (2007). The Inventory of Children's Individual Differences: Development and validation of a short version. Journal of Personality Assessment, 89(2), 162-166. https://doi.org/10.1080/00223890701468550 
Denissen, J. J. A., van Aken, M. A. G., Penke, L., \& Wood, D. (2013). Self-regulation underlies temperament and personality: An integrative developmental framework. Child Development Perspectives, 7(4), 255-260. https://doi.org/10.1111/cdep.12050

DeYoung, C. G. (2006). Higher-order factors of the Big Five in a multi-informant sample. Journal of Personality and Social Psychology, 91(6), 1138-1151. https://doi.org/10.1037/0022-3514.91.6.1138

Digman, J. M. (1997). Higher-order factors of the Big Five. Journal of Personality and Social Psychology, 73(6), 1246-1256. https://doi.org/10.1037/0022-3514.73.6.1246

Duhig, A. M., Renk, K., Epstein, M. K., \& Phares, V. (2006). Interparental agreement on internalizing, externalizing, and total behavior problems: A meta-analysis. Clinical Psychology: Science and Practice, 7(4), 435-453. https://doi.org/10.1093/clipsy.7.4.435

Durbin, C. E., Hayden, E. P., Klein, D. N., \& Olino, T. M. (2007). Stability of laboratoryassessed temperamental emotionality traits from ages 3 to 7. Emotion, 7(2), 388-399. https://doi.org/10.1037/1528-3542.7.2.388

Ferguson, C. J. (2010). A meta-analysis of normal and disordered personality across the life span. Journal of Personality and Social Psychology, 98(4), 659-667. https://doi.org/10.1037/a0018770

Fraley, R. C., \& Roberts, B. W. (2005). Patterns of continuity: A dynamic model for conceptualizing the stability of individual differences in psychological constructs across the life course. Psychological Review, 112(1), 60-74. https://doi.org/10.1037/0033295X.112.1.60

Graham, E. K., Rutsohn, J. P., Turiano, N. A., Bendayan, R., Batterham, P. J., Gerstorf, D., Katz, M. J., Reynolds, C. A., Sharp, E. S., Yoneda, T. B., Bastarache, E. D., Elleman, L. G., 
Zelinski, E. M., Johansson, B., Kuh, D., Barnes, L. L., Bennett, D. A., Deeg, D. J. H., Lipton, R. B., ... Mroczek, D. K. (2017). Personality predicts mortality risk: An integrative data analysis of 15 international longitudinal studies. Journal of Research in Personality, 70, 174-186. https://doi.org/10.1016/j.jrp.2017.07.005

Halverson, C. F., Havill, V. L., Deal, J. E., Baker, S. R., Victor, J. B., Pavlopoulos, V., Besevegis, E., \& Wen, L. (2003). Personality Structure as Derived from Parental Ratings of Free Descriptions of Children: The Inventory of Child Individual Differences. Journal of Personality, 71(6), 995-1026. https://doi.org/10.1111/1467-6494.7106005

Hampson, S. E., \& Goldberg, L. R. (2006). A first large cohort study of personality trait stability over the 40 years between elementary school and midlife. Journal of Personality and Social Psychology, 91(4), 763-779. https://doi.org/10.1037/0022-3514.91.4.763

Hogan, J., \& Roberts, B. W. (1996). Issues and non-issues in the fidelity-bandwidth trade-off. Journal of Organizational Behavior, 17(6), 627-637. https://doi.org/10.1002/(SICI)10991379(199611)17:6<627::AID-JOB2828>3.0.CO;2-F

Hudson, N. W., \& Roberts, B. W. (2016). Social investment in work reliably predicts change in conscientiousness and agreeableness: A direct replication and extension of Hudson, Roberts, and Lodi-Smith (2012). Journal of Research in Personality, 60, 12-23. https://doi.org/10.1016/j.jrp.2015.09.004

Hudson, N. W., Roberts, B. W., \& Lodi-Smith, J. (2012). Personality trait development and social investment in work. Journal of Research in Personality, 46(3), 334-344. https://doi.org/10.1016/j.jrp.2012.03.002

Jackson, J. J., Bogg, T., Walton, K. E., Wood, D., Harms, P. D., Lodi-Smith, J., Edmonds, G. W., \& Roberts, B. W. (2009). Not all conscientiousness scales change alike: A 
multimethod, multisample study of age differences in the facets of conscientiousness. Journal of Personality and Social Psychology, 96(2), 446-459. https://doi.org/10.1037/a0014156

Jang, K. L., McCrae, R. R., Angleitner, A., Riemann, R., \& Livesley, W. J. (1998). Heritability of Facet-Level Traits in a Cross-Cultural Twin Sample: Support for a Hierarchical Model of Personality. Journal of Personality and Social Psychology, 74(6), 1556-1565.

Kopala-Sibley, D. C., Olino, T., Durbin, E., Dyson, M. W., \& Klein, D. N. (2018). The stability of temperament from aarly childhood to early adolescence: A multi-method, multiinformant examination. European Journal of Personality, 32(2), 128-145. https://doi.org/10.1002/per.2151

Kushner, S. C., \& Tackett, J. L. (2017). Parent and Adolescent Agreement for Reports of Life Stressors. Assessment, 24(2), 143-156. https://doi.org/10.1177/1073191115607972

Laceulle, O. M., Nederhof, E., Karreman, A., Ormel, J., \& Aken, M. A. G. (2012). Stressful events and temperament change during early and middle adolescence: The TRAILS study. European Journal of Personality, 26(3), 276-284. https://doi.org/10.1002/per.832

Little, R. J., \& Rubin, D. B. (2014). Statistical analysis with missing data (Vol. 333). John Wiley \& Sons, Inc.

Lodi-Smith, J., \& Roberts, B. W. (2007). Social investment and personality: A meta-analysis of the relationship of personality traits to investment in work, family, religion, and volunteerism. Personality and Social Psychology Review, 11(1), 68-86. https://doi.org/10.1177/1088868306294590

Luan, Z., Hutteman, R., Denissen, J. J. A., Asendorpf, J. B., \& van Aken, M. A. G. (2017). Do you see my growth? Two longitudinal studies on personality development from 
childhood to young adulthood from multiple perspectives. Journal of Research in Personality, 67, 44-60. https://doi.org/10.1016/j.jrp.2016.03.004

McCrae, R. R. (2015). A more nuanced view of reliability: Specificity in the trait hierarchy. Personality and Social Psychology Review, 19(2), 97-112. https://doi.org/10.1177/1088868314541857

McCrae, R. R., Costa Jr, P. T., Terracciano, A., Parker, W. D., Mills, C. J., De Fruyt, F., \& Mervielde, I. (2002). Personality trait development from age 12 to age 18: Longitudinal, cross-sectional and cross-cultural analyses. Journal of Personality and Social Psychology, 83(6), 1456-1468. https://doi.org/10.1037/0022-3514.83.6.1456

Mendle, J., Turkheimer, E., \& Emery, R. E. (2007). Detrimental psychological outcomes associated with early pubertal timing in adolescent girls. Developmental Review, 27(2), 151-171. https://doi.org/10.1016/j.dr.2006.11.001

Meredith, W. (1993). Measurement invariance, factor analysis and factorial invariance. Psychometrika, 58(4), 525-543. https://doi.org/10.1007/BF02294825

Mervielde, I., \& De Fruyt, F. (1999). Construction of the Hierarchical Personality Inventory for Children (HiPIC). In Personality psychology in Europe: Proceedings of the Either European Conference on Personality Psychology (pp. 107-127). Tilburg University Press.

Mõttus, R., Bates, T. C., Condon, D. M., Mroczek, D., \& Revelle, W. (2019). Leveraging a more nuanced view of personality: Narrow characteristics predict and explain variance in life outcomes [Preprint]. PsyArXiv. https://psyarxiv.com/4q9gv/ 
Mroczek, D. K., \& Spiro, A. (2007). Personality change influences mortality in older men. Psychological Science, 18(5), 371-376. https://doi.org/10.1111/j.14679280.2007.01907.x

Ong, X. L., Hong, R. Y., Tsai, F.-F., \& Tan, S. H. (2018). Becoming more or less mature? The decline of self-control in middle childhood. Journal of Personality, 1-14. https://doi.org/10.1111/jopy.12434

Paunonen, S. V., \& Ashton, M. C. (2001). Big five factors and facets and the prediction of behavior. Journal of Personality and Social Psychology, 81(3), 524-539.

Paunonen, S. V., Rothstein, M. G., \& Jackson, D. N. (1999). Narrow reasoning about the use of broad personality measures for personnel selection. Journal of Organizational Behavior, 20(3), 389-405. https://doi.org/10.1002/(SICI)1099-1379(199905)20:3<389::AIDJOB917>3.0.CO;2-G

Poropat, A. E. (2014). A meta-analysis of adult-rated child personality and academic performance in primary education. British Journal of Educational Psychology, 84(2), 239-252. https://doi.org/10.1111/bjep.12019

Prinzie, P., \& Deković, M. (2008). Continuity and change of childhood personality characteristics through the lens of teachers. Personality and Individual Differences, 45(1), 82-88. https://doi.org/10.1016/j.paid.2008.03.002

Prinzie, P., \& Onghena, P. (2014). Cohort Sequential Design. In Encyclopedia of Statistics in Behavioral Science. John Wiley \& Sons, Inc.

R Core Team. (2017). R: A language and environment for statistical computing [R]. R Foundation for Statistical Computing. https://www.R-project.org/ 
Roberts, B. W. (2018). A revised sociogenomic model of personality traits. Journal of Personality, 86(1), 23-35. https://doi.org/10.1111/jopy.12323

Roberts, B. W., \& DelVecchio, W. F. (2000). The rank-order consistency of personality traits from childhood to old age: A quantitative review of longitudinal studies. Psychological Bulletin, 126(1), 3-25. https://doi.org/10.1037//0033-2909.126.1.3

Roberts, B. W., \& Jackson, J. J. (2008). Sociogenomic personality psychology. Journal of Personality, 76(6), 1523-1544. https://doi.org/10.1111/j.1467-6494.2008.00530.x

Roberts, B. W., \& Nickel, L. B. (2017). A critical evaluation of the Neo-Socioanalytic Model of personality. In Personality Development Across the Lifespan (pp. 157-177). Elsevier. https://doi.org/10.1016/B978-0-12-804674-6.00011-9

Roberts, B. W., Walton, K. E., \& Viechtbauer, W. (2006). Patterns of mean-level change in personality traits across the life course: A meta-analysis of longitudinal studies. Psychological Bulletin, 132(1), 1-25. https://doi.org/10.1037/0033-2909.132.1.1

Roberts, B. W., Wood, D., \& Smith, J. L. (2005). Evaluating Five Factor Theory and social investment perspectives on personality trait development. Journal of Research in Personality, 39(1), 166-184. https://doi.org/10.1016/j.jrp.2004.08.002

Rosseel, Y. (2012). lavaan: An R package for structural equation modeling. Journal of Statistical Software, 48(2), 1-36.

Schmidt, F. L., \& Hunter, J. E. (1996). Measurement error in psychological research: Lessons from 26 research scenarios. Psychological Methods, 1(2), 199-223. https://doi.org/10.1037/1082-989X.1.2.199

Schwaba, T., Robins, R. W., Grijalva, E., \& Bleidorn, W. (2019). Does Openness to Experience matter in love and work? Domain, facet, and developmental evidence from a 24-year 
longitudinal study. Journal of Personality, 87(5), 1074-1092.

https://doi.org/10.1111/jopy.12458

semTools Contributors. (2016). semTools: Useful tools for structural equation modeling (0.4-14) $[\mathrm{R}]$.

Shields, A. N., Reardon, K. W., Brandes, C. M., \& Tackett, J. L. (2019). The p factor in children: Relationships with executive functions and effortful control. Journal of Research in Personality, 82, 103853. https://doi.org/10.1016/j.jrp.2019.103853

Slobodskaya, H. R., \& Akhmetova, O. A. (2010). Personality development and problem behavior in Russian children and adolescents. International Journal of Behavioral Development, 34(5), 441-451. https://doi.org/10.1177/0165025409352825

Soto, C. J. (2019). How replicable are links between personality traits and consequential life outcomes? The Life Outcomes Of Personality Replication Project. Psychological Science, 30(5), 711-727.

Soto, C. J., \& John, O. P. (2017). The next Big Five Inventory (BFI-2): Developing and assessing a hierarchical model with 15 facets to enhance bandwidth, fidelity, and predictive power. Journal of Personality and Social Psychology, 113(1), 117-143. https://doi.org/10.1037/pspp0000096

Soto, C. J., John, O. P., Gosling, S. D., \& Potter, J. (2008). The developmental psychometrics of big five self-reports: Acquiescence, factor structure, coherence, and differentiation from ages 10 to 20. Journal of Personality and Social Psychology, 94(4), 718-737. https://doi.org/10.1037/0022-3514.94.4.718 
Soto, C. J., John, O. P., Gosling, S. D., \& Potter, J. (2011). Age differences in personality traits from 10 to 65: Big Five domains and facets in a large cross-sectional sample. Journal of Personality and Social Psychology, 100(2), 330-348. https://doi.org/10.1037/a0021717

Soto, C. J., \& Tackett, J. L. (2015). Personality traits in childhood and adolescence: Structure, development, and outcomes. Current Directions in Psychological Science, 24(5), 358362. https://doi.org/10.1177/0963721415589345

Statistics Canada. (2017). Education in Canada: Key results from the 2016 Census (No. 11-001X). https://www150.statcan.gc.ca/n1/en/daily-quotidien/171129/dq171129aeng.pdf?st=nupetS15

Steiger, J. H. (1980). Tests for comparing elements of a correlation matrix. Psychological Bulletin, 87(2), 254-251.

Steinberg, L., \& Sheffield Morris, A. (2001). Adolescent development. Annual Review of Psychology, 52, 83-110.

Sumter, S. R., Bokhorst, C. L., Steinberg, L., \& Westenberg, P. M. (2009). The developmental pattern of resistance to peer influence in adolescence: Will the teenager ever be able to resist? Journal of Adolescence, 32(4), 1009-1021. https://doi.org/10.1016/j.adolescence.2008.08.010

Tackett, J. L. (2011). Parent informants for child personality: Agreement, discrepancies, and clinical utility. Journal of Personality Assessment, 93(6), 539-544. https://doi.org/10.1080/00223891.2011.608763

Tackett, J. L., Herzhoff, K., Kushner, S. C., \& Rule, N. (2016). Thin slices of child personality: Perceptual, situational, and behavioral contributions. Journal of Personality and Social Psychology, 110(1), 150-166. https://doi.org/10.1037/pspp0000044 
Tackett, J. L., Kushner, S. C., De Fruyt, F., \& Mervielde, I. (2013). Delineating personality traits in childhood and adolescence: Associations across measures, temperament, and behavioral problems. Assessment, 20(6), 738-51.

https://doi.org/10.1177/1073191113509686

Tackett, J. L., Kushner, S. C., Herzhoff, K., Smack, A. J., \& Reardon, K. W. (2014). Viewing relational aggression through multiple lenses: Temperament, personality, and personality pathology. Development and Psychopathology, 26(3), 863-77.

https://doi.org/10.1017/S0954579414000443

Tackett, J. L., Slobodskaya, H. R., Mar, R. A., Deal, J., Halverson, C. F., Baker, S. R., Pavlopoulos, V., \& Besevegis, E. (2012). The hierarchical structure of childhood personality in five countries: Continuity from early childhood to early adolescence. Journal of Personality, 80(4), 847-879. https://doi.org/10.1111/j.14676494.2011.00748.x

Tackman, A. M., Srivastava, S., Pfeifer, J. H., \& Dapretto, M. (2017). Development of conscientiousness in childhood and adolescence: Typical trajectories and associations with academic, health, and relationship changes. Journal of Research in Personality, 67, 85-96. https://doi.org/10.1016/j.jrp.2016.05.002

Terracciano, A., McCrae, R. R., Brant, L. J., \& Costa, P. T. (2005). Hierarchical linear modeling analyses of the NEO-PI-R Scales in the Baltimore Longitudinal Study of Aging. Psychology and Aging, 20(3), 493-506. https://doi.org/10.1037/0882-7974.20.3.493

Turiano, N. A., Chapman, B. P., Gruenewald, T. L., \& Mroczek, D. K. (2015). Personality and the leading behavioral contributors of mortality. Health Psychology, 34(1), 51-60. https://doi.org/10.1037/hea0000038 
van den Akker, A. L., Deković, M., \& Prinzie, P. (2010). Transitioning to adolescence: How changes in child personality and overreactive parenting predict adolescent adjustment problems. Development and Psychopathology, 22(1), 151-63.

https://doi.org/10.1017/S0954579409990320

Van Oort, F. V. A., Greaves-Lord, K., Verhulst, F. C., Ormel, J., \& Huizink, A. C. (2009). The developmental course of anxiety symptoms during adolescence: The TRAILS study. Journal of Child Psychology and Psychiatry, 50(10), 1209-1217. https://doi.org/10.1111/j.1469-7610.2009.02092.x

van Scheppingen, M. A., Jackson, J. J., Specht, J., Hutteman, R., Denissen, J. J. A., \& Bleidorn, W. (2016). Personality trait development during the transition to parenthood: A test of social investment theory. Social Psychological and Personality Science, 7(5), 452-462. https://doi.org/10.1177/1948550616630032

Vazire, S. (2010). Who knows what about a person? The self-other knowledge asymmetry (SOKA) model. Journal of Personality and Social Psychology, 98(2), 281-300. https://doi.org/10.1037/a0017908

Watson, D., Ellickson-Larew, S., Stanton, K., Levin-Aspenson, H. F., Khoo, S., Stasik-O’Brien, S. M., \& Clark, L. A. (2019). Aspects of extraversion and their associations with psychopathology. Journal of Abnormal Psychology, 128(8), 777-794. https://doi.org/10.1037/abn0000459

Watson, D., Stasik, S. M., Ellickson-Larew, S., \& Stanton, K. (2015). Extraversion and psychopathology: A facet-level analysis. Journal of Abnormal Psychology, 124(2), 432446. https://doi.org/10.1037/abn0000051 
Weiss, A., \& Costa, P. T. (2005). Domain and facet personality predictors of all-cause mortality among medicare patients aged 65 to 100. Psychosomatic Medicine, 67(5), 724-733. https://doi.org/10.1097/01.psy.0000181272.58103.18

Weiss, D. J. (1982). Improving measurement quality and efficiency with adaptive testing. Applied Psychological Measurement, 6(4), 473-492. https://doi.org/10.1177/014662168200600408 